\title{
Review
}

\section{Towards Red Emissive Systems Based on Carbon Dots}

\author{
Spyridon Gavalas and Antonios Kelarakis *(1) \\ UCLan Research Centre for Smart Materials, School of Natural Sciences, University of Central Lancashire, \\ Preston PR1 2HE, UK; sgavalas@uclan.ac.uk \\ * Correspondence: akelarakis@uclan.ac.uk; Tel.: +44-1-772-4172
}

Citation: Gavalas, S.; Kelarakis, A. Towards Red Emissive Systems Based on Carbon Dots. Nanomaterials 2021, 11, 2089. https://doi.org/10.3390/ nano11082089

Academic Editor: Constantine D. Stalikas

Received: 3 July 2021

Accepted: 10 August 2021

Published: 17 August 2021

Publisher's Note: MDPI stays neutral with regard to jurisdictional claims in published maps and institutional affiliations.

\begin{abstract}
Carbon dots (C-dots) represent an emerging class of nontoxic nanoemitters that show excitation wavelength-dependent photoluminescence (PL) with high quantum yield (QY) and minimal photobleaching. The vast majority of studies focus on C-dots that exhibit the strongest PL emissions in the blue/green region of the spectrum, while longer wavelength emissions are ideal for applications such as bioimaging, photothermal and photodynamic therapy and light-emitting diodes. Effective strategies to modulate the PL emission of C-dot-based systems towards the red end of the spectrum rely on extensive conjugation of $\mathrm{sp}^{2}$ domains, heteroatom doping, solvatochromism, surface functionalization and passivation. Those approaches are systematically presented in this review, while emphasis is given on important applications of red-emissive suspensions, nanopowders and polymer nanocomposites.
\end{abstract}

Keywords: fluorescence; carbon dots; red-emitting; bioimaging; light-emitting diodes

\section{Introduction}

The dynamic presence of carbon dots (C-dots) in the field of nanoemitters over the last 15 years is directly related to their unique combination of three desired characteristics: inexpensive preparation, nontoxic nature and superior photophysical properties in terms of light absorption, chemiluminescence, electroluminescence, phosphorescence and upconversion [1-5]. Typically, C-dots are spherical nanoparticles with size 2-20 nm that are composed of $\mathrm{C}, \mathrm{O}$ and $\mathrm{H}$ along with heteroatoms such as $\mathrm{N}, \mathrm{P}$ and $\mathrm{S}$.

Their carbogenic cores can be predominantly amorphous or highly graphitic in nature [6], while the term graphene quantum dots (GQDs) is typically reserved for nanodisks of single- or few-layered graphene sheets [7]. In that sense, GQDS are considered as a distinct subgroup of $\mathrm{C}$-dots and are synthesized by various strategies including chemical vapor deposition on hexagonal boron nitride substrates [8], all-organic synthesis starting from polyphenylene dendrimers [9] and ring opening of fullerenes adsorbed to Ru metal terraces [10]. Alternatively, GQDs can be prepared by oxidation or electrooxidation of carbon-rich sources such as coal [11], carbon black [12], graphite [13], carbon fibres [14] and carbon nanotubes (CNT) [15].

Well-defined C-dots are prepared at a large scale following hydrothermal, microwave and calcination protocols performed on a wide range of feedstock materials, including renewable and abundant resources such as crude biomass [16], coffee beans [17], fruit juice [18], etc. Pyrolytic decomposition of suitable precursors gives rise to molecular fluorophores that are embedded within the carbogenic cores or are adsorbed on their surfaces $[19,20]$. For example, thermal treatment of urea and citric acid (CA) generates blue-emissive citrazinic acid and green-emissive 4-hydroxy-1H-pyrrolo(3,4-c) pyridine1,3,6(2H,5H)-trione [21].

The PL properties of aqueous solutions of C-dots have been systematically investigated with emphasis on theragnostics [22], gene delivery [22], drug delivery [23], antimicrobial applications [24], bioimaging [25] and biosensing [26]. At the same time the PL properties of polymer-based nanocomposites $[27,28]$ and powder formulations based on 
C-dots $[29,30]$ are directly relevant to nanoforensics [29,30], light-emitting diodes [31] and catalytic platforms [32].

In contrast to conventional semiconducting quantum dots that are based on heavy metals, C-dots are considered as nontoxic, biocompatible and environmentally benign nanomaterials. Nevertheless, it has been demonstrated that surface functionalization can dramatically modify their cytotoxicity as well as cell uptake and intercellular trafficking [33,34].

Although a large variety of blue/green-emissive C-dots with advanced PL properties have been developed, it has been demonstrated that extensive $\pi$-conjugated domains, high levels of surface oxidation, incorporation of heteroatoms such as N, S and P and solvatochromism can give rise to red-shifted emissions [35,36]. It has been recently suggested that the red/NIR-emissive signals recorded on C-dot based systems stem from organic-like dye molecules encapsulated within carbonaceous nanostructures and might not be related to the intrinsic properties of nanoparticles [37]. This approach, however, might not explain the behaviour observed in GQDS and in related systems not prepared via pyrolysis. There is general consensus that pyrolytic treatments of precursor molecules give rise to complex mixtures of carbonaceous nanoparticles, crosslinked systems and organic molecules, necessitating further systematic studies in order to accurate deconvolute and identify the emissive contributions of each one of those components.

In this review we present promising strategies for the synthesis of C-dot-based systems with predominantly red-shifted optical signals. Particular attention is given to the preparation of red-emissive liquid suspensions, polymer nanocomposites and nanopowder formulations. The distinct advantages of those nanomaterials in emerging applications such as bioimaging, biosensing, photothermal and photodynamic therapy, light-emitting diodes, pollutant detection and nanoforensics are highlighted.

\section{Discussion}

\subsection{Strategies to Generate Red-Shifted C-Dots}

The main strategies that give rise to red-shifted C-dots rely on: (i) heteroatom doping, (ii) extensive conjugation length, (iii) surface functionalization and passivation and (iv) solvatochromism.

\subsubsection{Heteroatom Doping}

Heteroatom doping is a well-explored strategy to modify the electronic and optical properties of C-dots, ultimately leading to red-shifted C-dots [38]. It has been supported that $\mathrm{N}$ doping can reduce the bandgap and improve bandgap uniformity of $\mathrm{C}$-dots, thus enhancing red emissions with a narrow full width at half maximum. Moreover, B and S doping leads to reduced nonradiative recombinations, in essence intensifying red signals. Incorporation of La results in local structural rearrangements, increased charge transfer and ultimately stronger red emissions [35].

To that end, Hola et al. [39] synthesized N-doped graphitic C-dots following the solvothermal treatment of urea and CA in formamide (Figure 1a) that were subsequently subjected to column chromatography yielding blue- (b-C-dots), green- (g-C-dots), yellow(y-C-dots) and red- (r-C-dots) emissive fractions as shown in Figure $1 \mathrm{~b}, \mathrm{c}, \mathrm{d}, \mathrm{e}$, respectively. In water, at $\lambda_{\mathrm{ex}}=440 \mathrm{~nm}$, the QY of b-C-dots, g-C-dots, $\mathrm{y}$-C-dots and r-C-dots were $13.3 \%$, $10.0 \%, 11.6 \%$ and $4.0 \%$, respectively. Transmission electron microscopy (TEM) imaging suggested that the average diameter $\left(\mathrm{d}_{\mathrm{av}}\right)$ of these C-dots was 2-3 nm (Figure 2a-d). X-ray photoelectron spectroscopy (XPS) indicated a lower concentration of oxygen, hydroxyl and carboxyl groups and an increased content of graphitic nitrogen for $\mathrm{y}$-C-dots and $\mathrm{r}-\mathrm{C}$-dots (Figure 2e-1), while nitrogen stemming from surface amide groups was dominant in b-Cdots and g-C-dots. Fourier transform infrared spectroscopy (FT-IR) confirmed the presence of carboxylic $\mathrm{C}=\mathrm{O}$ bonds and surface $\mathrm{C}-\mathrm{N}$ bonds for $\mathrm{b}-\mathrm{C}$-dots and $\mathrm{g}$ - $\mathrm{C}$-dots, whereas the most pronounced FT-IR peaks were ascribed to $\mathrm{C}-\mathrm{N}=$ and $\mathrm{C}=\mathrm{N}$ bonds for $\mathrm{y}-\mathrm{C}$-dots and $\mathrm{r}$-C-dots, verifying the dominant role of graphitic nitrogen for the red-shifted fractions. 
a
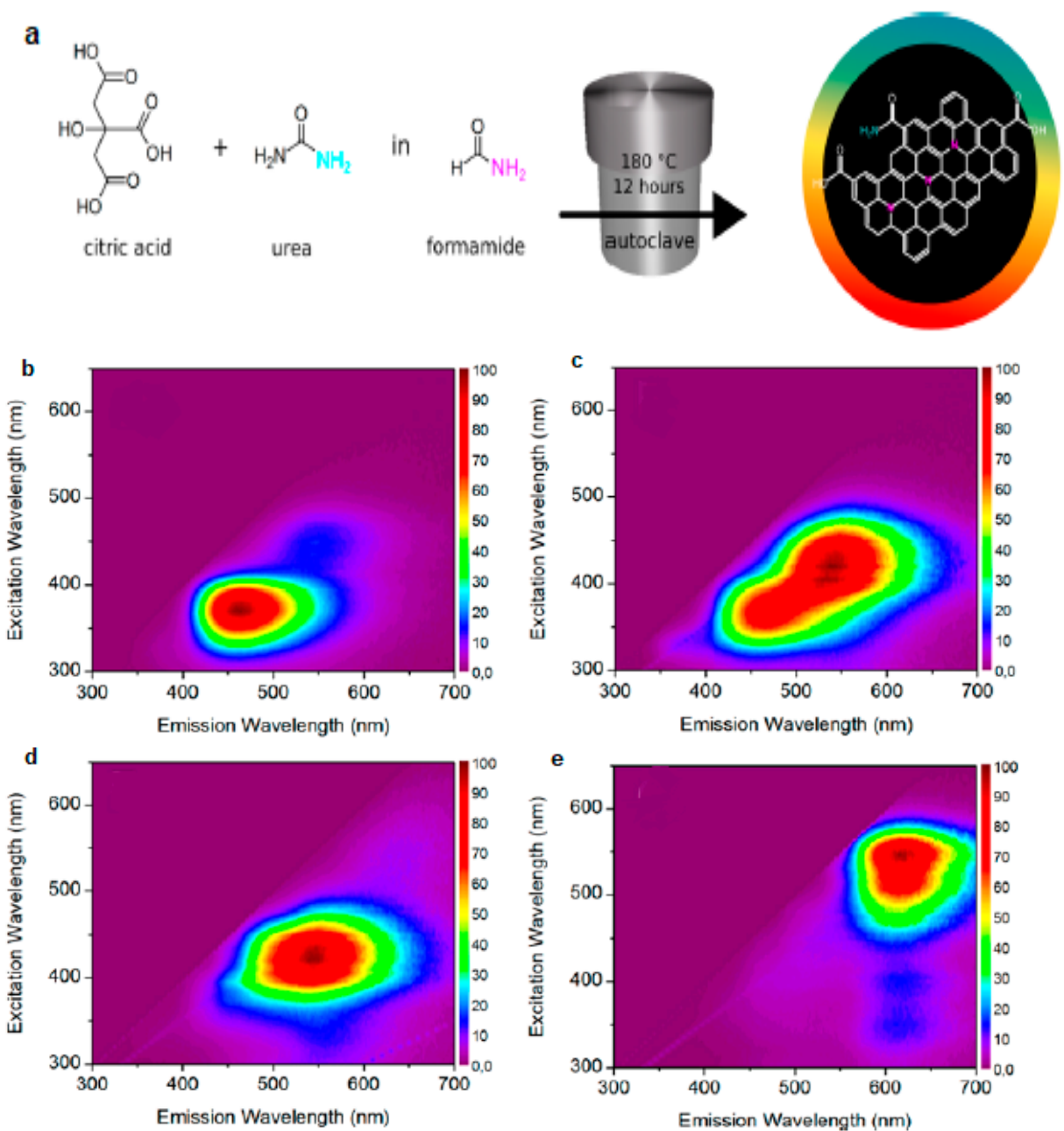

Figure 1. (a) Schematic illustration of the synthesis followed to generate a family of C-dots from $\mathrm{CA} /$ urea in formamide. (b-e) Fluorescence excitation-emission map of: (b) b-C-dots, (c) g-C-dots, (d) y-C-dots and (e) r-C-dots. Reprinted (adapted) with permission from [39]. Copyright 2021 American Chemical Society.

Moreover, Ding et al. [40] fabricated red graphitic C-dots $\left(Q Y=28 \%\right.$ at $\left.\lambda_{\mathrm{ex}}=533 \mathrm{~nm}\right)$ with $\mathrm{d}_{\mathrm{av}}=4.6 \mathrm{~nm}$ by means of solvothermal treatment of lemon juice in ethanol $\left(\lambda_{\mathrm{ex}}\right.$ stands for excitation wavelength). The PL spectra of these C-dots suggested $\lambda_{\text {ex }}$-dependent behaviour, with the maximum of their emission peak at $\lambda_{\max }=615 \mathrm{~nm}$. FT-IR suggested the presence of $\mathrm{O}-\mathrm{H}, \mathrm{N}-\mathrm{H},-\mathrm{COOH}$ and $\mathrm{C}-\mathrm{O}$ on their surface, while $\mathrm{C}=\mathrm{C} / \mathrm{C}=\mathrm{N}$ and $\mathrm{C}-\mathrm{N}$ vibrations were attributed to the polyaromatic structures of the carbogenic cores. XPS confirmed the presence of $\mathrm{C}-\mathrm{C} / \mathrm{C}=\mathrm{C}, \mathrm{C}-\mathrm{N}, \mathrm{C}-\mathrm{O}, \mathrm{C}=\mathrm{O} / \mathrm{C}=\mathrm{N}$ and $\mathrm{COOH}$ groups along with the presence of pyridinic $\mathrm{C}-\mathrm{N}-\mathrm{C}$, pyrrolic $\mathrm{C}_{2}-\mathrm{N}-\mathrm{H}$ and graphitic $\mathrm{N}-\mathrm{C}_{3}$ groups.

Capitalizing on similar concepts, Guo et al. [41] used various ratios of two types of functionalized polythiophene derivatives to prepare a series of graphitic C-dots with tuneable PL emissions ranging from blue to near infrared (NIR). All C-dots consisted of C, $\mathrm{O}$ and $\mathrm{S}$, while the $\mathrm{N}$ content was higher for the red-shifted fractions. Pan et al. [42] synthesized graphitic C-dots with $\mathrm{d}_{\mathrm{av}}=6.8 \mathrm{~nm}$, through microwave heating of CA and formamide solution in an autoclave with QY close to $11.9 \%, 16.7 \%$ and $26.2 \%$ at $\lambda_{\mathrm{ex}}=360 \mathrm{~nm}, 450 \mathrm{~nm}$ and $540 \mathrm{~nm}$, respectively. Likewise, Pan et al. [43] followed microwave-assisted heating of glutathione formamide to synthesize graphitic NIR-emitting C-dots with $\mathrm{d}_{\mathrm{av}}=2.9 \mathrm{~nm}$ and $\mathrm{QY}=16.8 \%$ at $\lambda_{\mathrm{ex}}=420 \mathrm{~nm}$. 

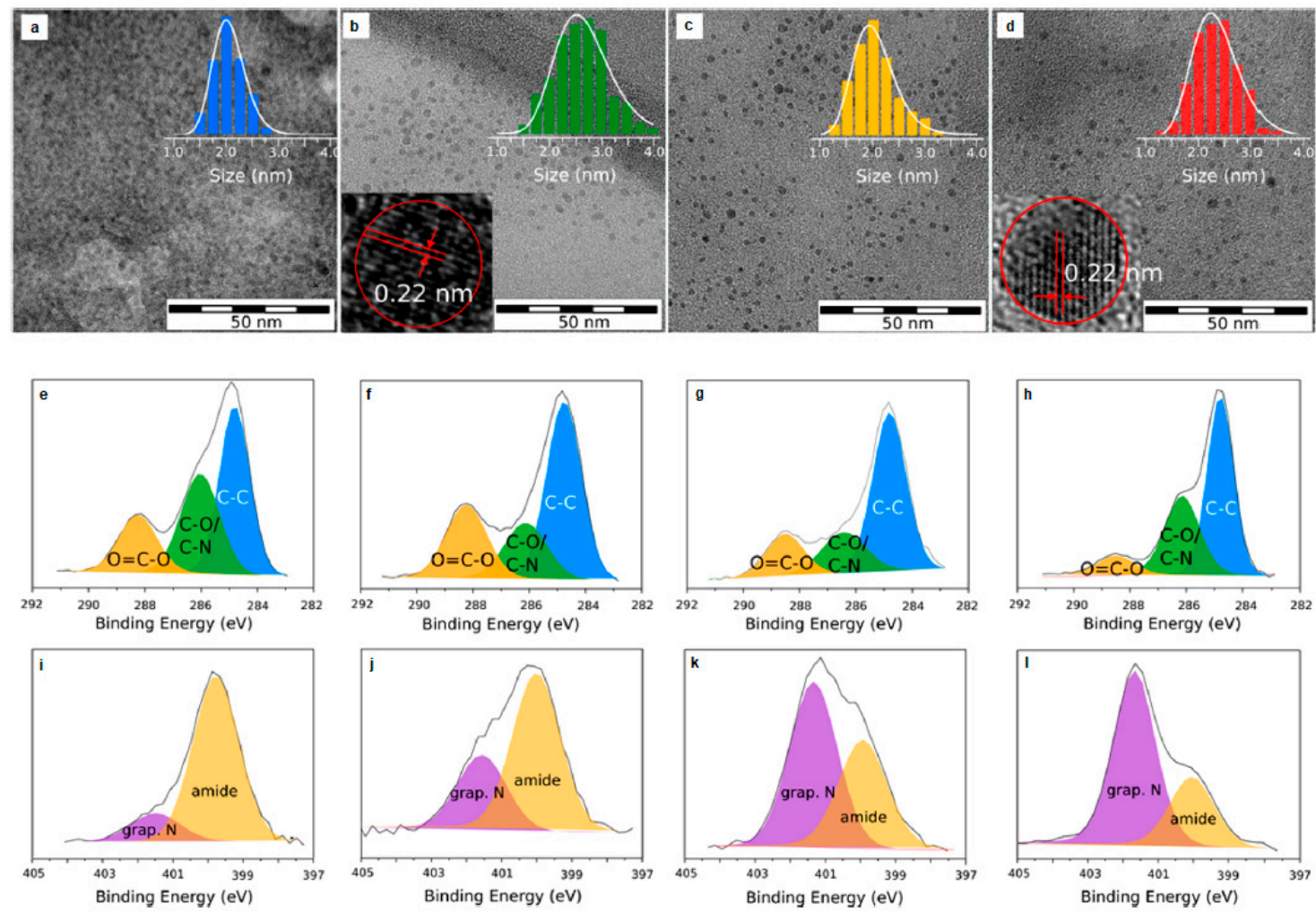

Figure 2. TEM images of: (a) b-C-dots, (b) g-C-dots, (c) y-C-dots and (d) r-C-dots with diameter histogram and HR-TEM images for g-C-dots and r-C-dots in the inset. High-resolution C 1 s and N 1s XPS spectra for (e,i) b-C-dots; (f,j) g-C-dots; (g,k) y-C-dots and (h,l) r-C-dots. Reprinted (adapted) with permission from [39]. Copyright 2021 American Chemical Society.

In terms of multiheteroatom doping, Huang et al. [44] followed a hydrothermal method using 3-aminobenzeneboronic acid and 2,5-diaminobenzenesulfonic acid as precursors to synthesize N, B and S codoped C-dots (NBS-C-dots) with $\mathrm{d}_{\mathrm{av}}=2.8 \mathrm{~nm}$ and $\mathrm{QY}=11.6 \%$ at $\lambda_{\mathrm{ex}}=520 \mathrm{~nm}$. NBS-C-dots showed $\lambda_{\text {ex }}$-independent behaviour with $\lambda_{\max }=605 \mathrm{~nm}$ for $410 \mathrm{~nm} \leq \lambda_{\mathrm{ex}} \leq 530 \mathrm{~nm}$ (Figure 3a). The high-resolution C 1s XPS spectrum indicates the presence of $\mathrm{C}-\mathrm{B}(283.89 \mathrm{eV}), \mathrm{C}-\mathrm{C} / \mathrm{C}=\mathrm{C}(284.78 \mathrm{eV}), \mathrm{C}-\mathrm{O} / \mathrm{C}-\mathrm{S}$ $(285.55 \mathrm{eV})$ and $\mathrm{C}-\mathrm{N} / \mathrm{C}-\mathrm{O}(286.00 \mathrm{eV})$ (Figure 3b). The N 1s XPS spectrum can be deconvoluted into three main peaks at $401.95 \mathrm{eV}, 401.20 \mathrm{eV}$ and $399.48 \mathrm{eV}$, which are related to $\mathrm{N}-\mathrm{H}, \mathrm{C}-\mathrm{N}$ and $\mathrm{C}-\mathrm{N}-\mathrm{C}$, respectively (Figure 3c). The B 1s XPS spectrum reveals three peaks at $192.23 \mathrm{eV}, 191.10 \mathrm{eV}$ and $190.43 \mathrm{eV}$, corresponding to B-S, B-O and B-C, respectively (Figure 3d). The S 2p XPS spectrum indicates two peaks at $167.90 \mathrm{eV}$ and $168.45 \mathrm{eV}$, which relate to the $\mathrm{S} 2 \mathrm{p} 3 / 2$ and $\mathrm{S} 2 \mathrm{p} 1 / 2$ spectra of the $\mathrm{C}-\mathrm{S}-\mathrm{C}$ bond, and one peak at $167.9 \mathrm{eV}$, which is attributed to $-\mathrm{C}-\mathrm{SO}_{\mathrm{x}}-(\mathrm{x}=2,3$, and 4$)$ (Figure 3e). The $\mathrm{O} 1 \mathrm{~s}$ XPS spectrum shows three peaks at $532.93 \mathrm{eV}, 532.08 \mathrm{eV}$ and $531.15 \mathrm{eV}$, ascribed to $\mathrm{O}=\mathrm{C}-\mathrm{O}, \mathrm{C}-\mathrm{O}$ and $\mathrm{C}=\mathrm{O}$, respectively (Figure 3f). FT-IR spectroscopy suggests the presence of $\mathrm{O}-\mathrm{H}, \mathrm{N}-\mathrm{H}$ bonds, $-\mathrm{SCN}$ - groups and $\mathrm{C}=\mathrm{O}, \mathrm{C}=\mathrm{C}, \mathrm{C}-\mathrm{N}, \mathrm{C}-\mathrm{C}, \mathrm{C}-\mathrm{S}$ and $\mathrm{C}-\mathrm{O}-\mathrm{C}$ bonds, along with $\mathrm{B}-\mathrm{O}, \mathrm{B}-\mathrm{O}-\mathrm{H}$, $\mathrm{C}-\mathrm{B}$ and $\mathrm{B}-\mathrm{O}-\mathrm{H}$ bonds.

$\mathrm{Xu}$ et al. [45] followed a hydrothermal treatment of L-methionine and urea using water and dimethylformamide (DMF) as the solvent to produce red- (N,S-doped) and blue-emitting (N-doped) graphitic C-dots, respectively. Miao et al. [46] followed a hydrothermal treatment of $\mathrm{CA}$ and thiourea in acetone to synthesize graphitic red-emitting $\mathrm{N}, \mathrm{S}$-doped C-dots with QY $=22 \%$ in water. Ge et al. [47] followed a hydrothermal treatment of polythiophene phenylpropionic acid (PPA) to synthesize graphitic, red-emissive S-doped C-dots with $\mathrm{d}_{\mathrm{av}}=10 \mathrm{~nm}$ exhibiting $\lambda_{\mathrm{ex}}$-independent properties with $\mathrm{QY}=2.3 \%$. Yang et al. [48] followed a hydrothermal treatment of 2,5-diaminobenzenesulfonic acid to 
synthesize graphitic, red-emissive $\mathrm{N}, \mathrm{S}$-doped C-dots with $\mathrm{d}_{\mathrm{av}}=4.9 \mathrm{~nm}$ and $\mathrm{QY}=2.7 \%$ at $\lambda_{\mathrm{ex}}=500 \mathrm{~nm}$.
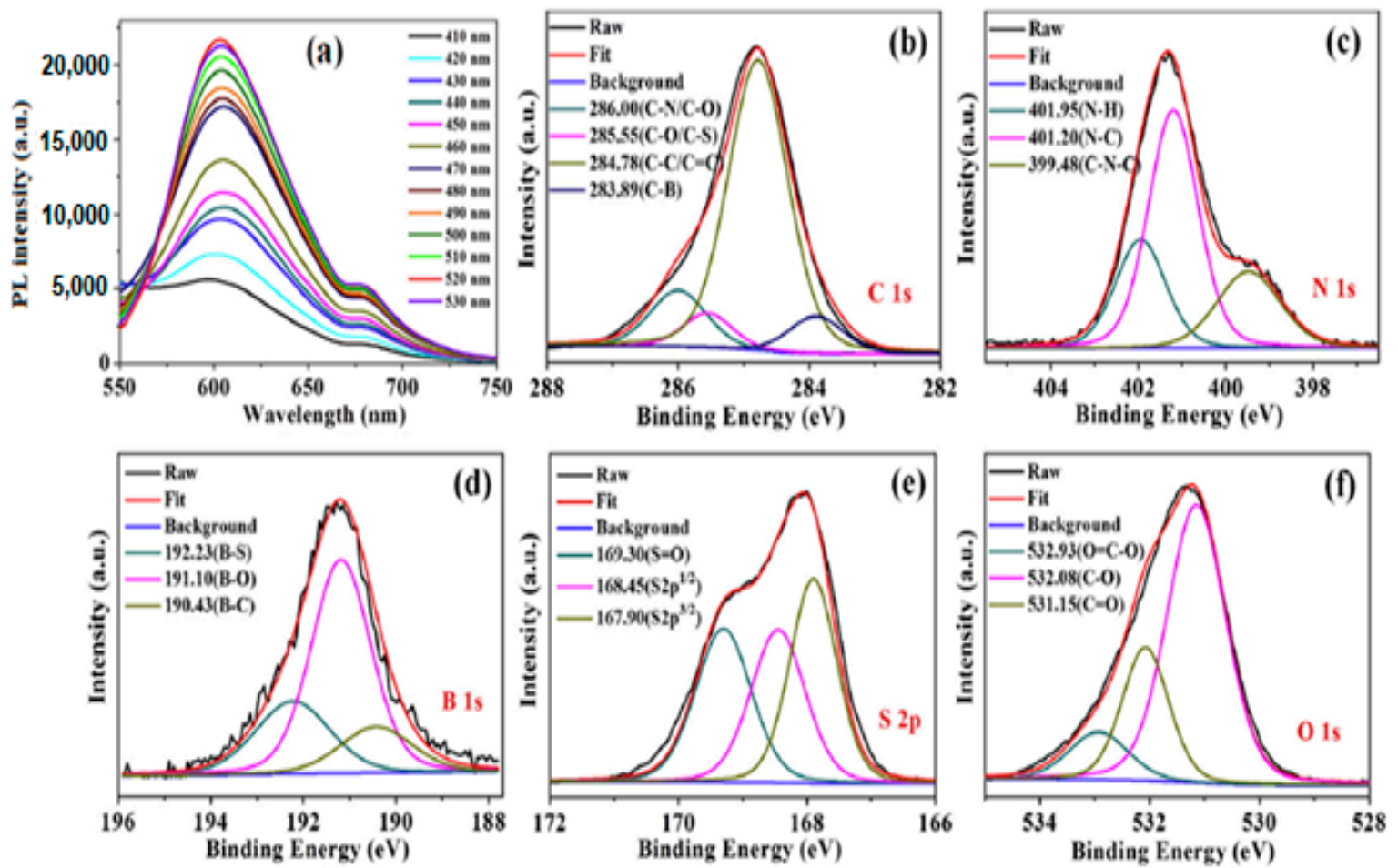

Figure 3. (a) PL spectra of NBS-C-dots with $\lambda_{\mathrm{ex}}$ ranging from $410 \mathrm{~nm}$ to $530 \mathrm{~nm}$. C 1s (b), N 1s (c), B 1s (d), S 2p (e), and O 1s XPS spectrum (f) of NBS-C-dots. Reprinted (adapted) with permission from [44]. Copyright 2021 Elsevier.

In situ chromophore doping can lead to red-shifted C-dots by introducing new electron transition pathways that alter their highest occupied molecular orbital and lowest unoccupied molecular orbital (HOMO-LUMO) levels. Karami et al. [49] developed a synthetic procedure to synthesize chromophore-doped graphitic C-dots with $d_{a v}=5 \mathrm{~nm}$ via a hydrothermal treatment of glucose and 3-nitroaniline dissolved in sulfuric acid. The C-dots exhibited three $\lambda_{\text {ex }}$-independent emissions (blue, red and yellow) under acidic, neutral and alkaline environments, respectively. At $\mathrm{pH}=2$ the C-dots showed $\lambda_{\max }=385 \mathrm{~nm}$ $(\mathrm{QY}=43.0 \%)$, but at $\mathrm{pH}=3$ a weak red peak appeared along with the dominant blue peak. Upon increasing the $\mathrm{pH}$, the intensity of the blue emission peak declined, whereas the red emission peak was enhanced, and at $\mathrm{pH}=7$ there was a single emission peak at $\lambda_{\max }=610 \mathrm{~nm}(\mathrm{QY}=14.4 \%)$, which at $\mathrm{pH}=12$ shifted to $\lambda_{\max }=565 \mathrm{~nm}(\mathrm{QY}=24.3 \%)$. FT-IR spectra showed peaks related to $\mathrm{O}-\mathrm{H}$ and $\mathrm{N}-\mathrm{H}$ groups, $\mathrm{C}-\mathrm{H}$ stretching vibrations, the $\mathrm{C}=\mathrm{O}$ band of amide and carbonyl groups, $\mathrm{C}=\mathrm{C}$ stretching $/ \mathrm{N}-\mathrm{H}$ bending bands and $\mathrm{C}-\mathrm{S} / \mathrm{C}-\mathrm{N} / \mathrm{C}-\mathrm{O}$ stretching vibration bands. At the same time, a pH-dependent FT-IR peak centred at $1545 \mathrm{~cm}^{-1}$ was attributed to the presence of azo groups $(-\mathrm{N}=\mathrm{N})$, showing maximum intensity at neutral $\mathrm{pH}$ and minimum intensity at acidic $\mathrm{pH}$.

\subsubsection{Extensive Conjugation Length}

Early studies indicated the crucial role of quantum confinement in $\pi$-bonded hexagonal carbon clusters on the broadband emission of carbon-based films [50]. More recently, it has been shown that the HOMO-LUMO gap energy decreases as the size of GQDs increases [51]. Moreover, it has been demonstrated that the emission wavelength shows a linear size dependence in defect-free, functionality-free, zigzag-edged GQDs and that the fluorescence emission covers a broad spectrum from deep UV $\left(\lambda_{\mathrm{em}}=235.2 \mathrm{~nm}\right)$ to NIR $\left(\lambda_{\mathrm{em}}=999.5 \mathrm{~nm}\right)$ as the size varies from $0.46 \mathrm{~nm}$ to $2.31 \mathrm{~nm}$ [52]. At the same time, the 
presence of armchair edge widens the band gap in and blue shifts the emissive signals of GQDs [53].

Yeh et al. [54] relied on the oxidation of GO sheets to generate GQDs that were separated (via polyethersulfone membranes with different cutoff molecular weights) to fractions with $\mathrm{d}_{\mathrm{av}}=1.0 \mathrm{~nm}$ (QD10), $1.6 \mathrm{~nm}$ (QD16), $2.6 \mathrm{~nm}$ (QD26), $5.4 \mathrm{~nm}$ (QD54), $6.1 \mathrm{~nm}$ (QD61) and $7.9 \mathrm{~nm}$ (QD 79), all of which exhibited excitation-wavelength independent PL with $\lambda_{\max }$ at $460 \mathrm{~nm}, 490 \mathrm{~nm}, 520 \mathrm{~nm}, 540 \mathrm{~nm}, 560 \mathrm{~nm}$ and $580 \mathrm{~nm}$, respectively (Figure 4).

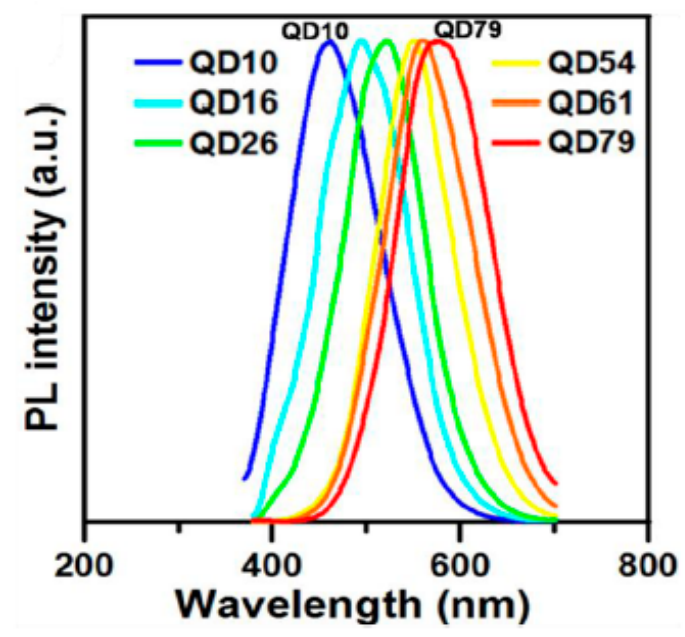

Figure 4. Normalized PL spectra $\left(\lambda_{\mathrm{ex}}=350 \mathrm{~nm}\right.$ ) of QD10, QD16, QD26, QD54, QD61 and QD79. Reprinted (adapted) with permission from [54]. Copyright 2021 American Chemical Society.

Li et al. [51] explored alkali-assisted electrooxidation of a graphite rod by applying different current densities to fabricate a series of C-dots and demonstrated that small- $(1.2 \mathrm{~nm})$, medium- (1.5-3 nm) and large-sized $(3.8 \mathrm{~nm})$ C-dots emit within the UV $(350 \mathrm{~nm})$, visible $(400-700 \mathrm{~nm})$ and NIR $(800 \mathrm{~nm})$ regions, respectively (Figure 5a,b). FT-IR spectroscopy indicated the presence of carbonyl $(\mathrm{C}=\mathrm{O})$ groups on the surface of these $\mathrm{C}$-dots that can be eliminated via hydrogen plasma treatment without altering the PL properties of C-dots, an effect that points to the dominant role of quantum confinement for this class of materials. Figure $5 \mathrm{c}$ suggests that as the size of the C-dots increases, the HOMO-LUMO energy gap decreases, and therefore the PL emission is shifted towards the NIR region of the spectra.
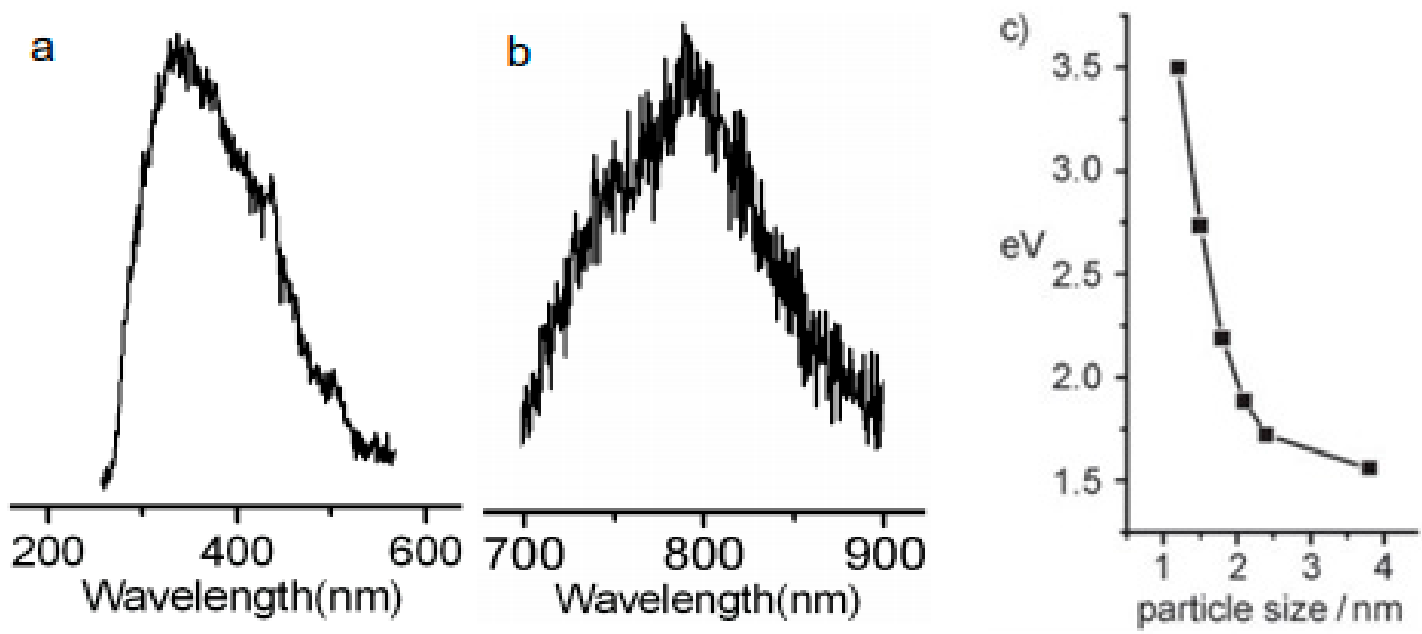

Figure 5. PL spectra of (a) small-sized C-dots $(1.2 \mathrm{~nm})$ and (b) large-sized C-dots $(3.8 \mathrm{~nm})$. (c) Size dependence of the bandgap in C-dots. Reprinted (adapted) with permission from [51]. Copyright 2021 John Wiley and Sons. 
Yuan et al. [55] followed solvothermal treatment of CA and diaminonaphthalene in ethanol and allowed different reaction times in the presence of concentrated sulfuric acid, yielding GQDs with $\mathrm{d}_{\mathrm{av}}=1.9 \mathrm{~nm}, 2.4 \mathrm{~nm}$. $3.8 \mathrm{~nm}, 4.9 \mathrm{~nm}$ and $6.7 \mathrm{~nm}$ emitting respectively within the blue, green, yellow, orange and red regions, in agreement with the expected behaviour owing to quantum confinement effects. Similar trends were confirmed by Tian et al. [56], who explored the solvothermal treatment of CA and urea in water, glycerol, DMF and their mixtures to generate C-dots with tuneable size and PL emissions.

\subsubsection{Surface Functionalization and Passivation}

Surface functionalization strategies have been shown to dramatically modify the PL properties of C-dots via defect and intrinsic state emission mechanisms [57] and charge transfer effects [58]. In principle, the presence of functional groups on C-dots generates structural defects and midgap states facilitating $\pi^{*} \rightarrow$ midgap states $\rightarrow \pi$ transitions, thus enhancing the red components on their PL spectra [59]. An interesting study showed that within a series of C-dots with similar size distribution and graphitization degree, the bandgap was gradually reduced upon increasing the degree of surface oxidation, leading to a pronounced red shift from 440 to $625 \mathrm{~nm}$ [60]. In electrochemically oxidized C-dots it was shown that the PL mode stemming from the organic fluorophores was blue-shifted, while the PL component originated by the carbogenic cores was red-shifted [61].

Xiong's group [60] synthesized a series of graphitic C-dots via hydrothermal treatment of urea and p-phenylenediamine (p-PD) yielding a mixture of four fractions $(A, B, C$ and $\mathrm{D}$ in Figure 6a) that could be separated via silica column chromatography because of their different polarities. TEM imaging indicated that all fractions consisted of C-dots with $\mathrm{d}_{\mathrm{av}}=2.6 \mathrm{~nm}$, while FT-IR spectra revealed the presence of $\mathrm{O}-\mathrm{H}, \mathrm{N}-\mathrm{H}, \mathrm{C}-\mathrm{O}$ and $-\mathrm{COOH}$ groups on their surfaces. XPS indicated a systematic enhancement of the oxygen content when moving from fraction $A$ to $D$, a trend that is accompanied by a systematic shift from blue to red PL emission at $\lambda_{\mathrm{ex}}=365 \mathrm{~nm}$. It has been suggested that as the population of surface oxygen atoms increases, the HOMO-LUMO bandgap gradually narrows, ultimately facilitating red PL emission (Figure 6b).
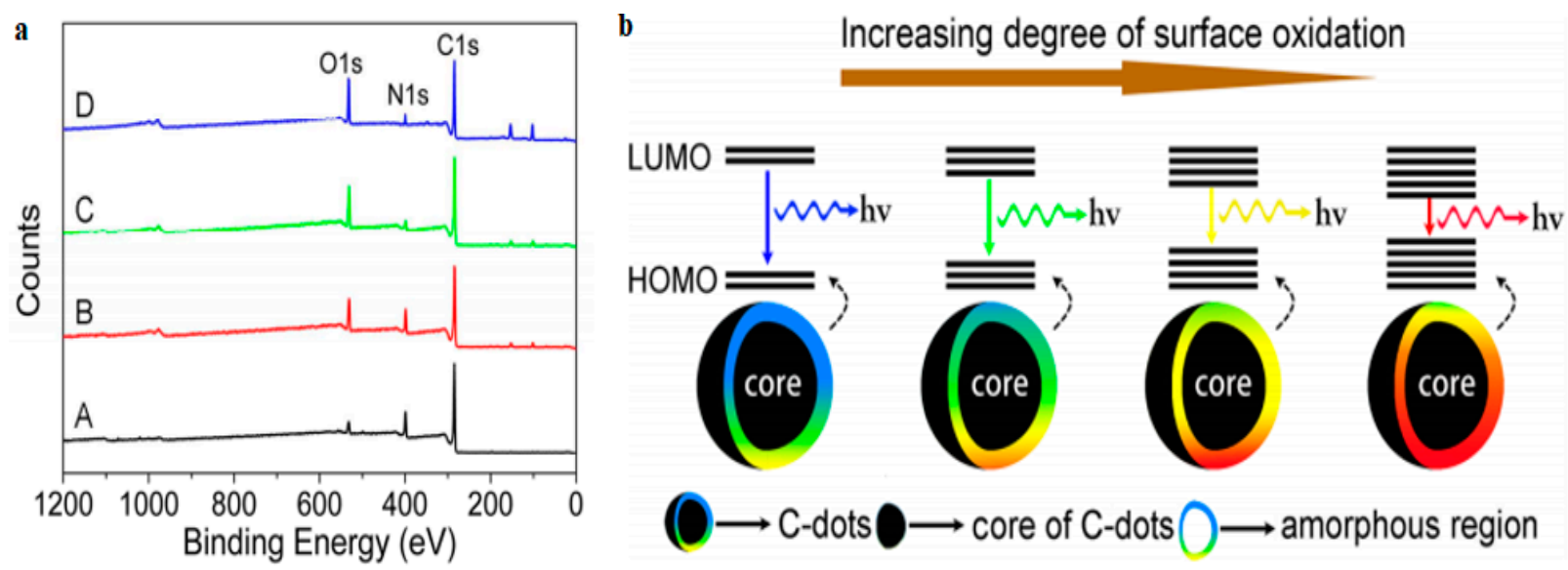

Figure 6. (a) XPS spectra of the fractions A, B, C and D. (b) Effect of the surface oxidation degree on the PL properties of C-dots (as the energy gap gets narrower, the photons' frequency decreases). Reprinted (adapted) with permission from [60]. Copyright 2021 American Chemical Society.

Liu et al. [62] followed a microwave-assisted pyrolysis of m-PD, o-PD and p-PD in formamide to generate three types of $\mathrm{C}$-dots that exhibited $\lambda_{\mathrm{ex}}$-independent emission with $\lambda_{\max }$ at $360 \mathrm{~nm}, 450 \mathrm{~nm}$ and $530 \mathrm{~nm}$, respectively. On the basis of FT-IR and XPS data, the authors demonstrated that the red-shifted C-dots exhibited a higher level of surface oxidation and possessed a larger population of amino groups on their surface. Zhang et al. [63] reported that blue-emitting C-dots (derived via pyrolysis of polyethylene glycol (PEG)) 
can be turned into green- and orange-emissive systems when treated thermally with PEG and 2,20-(ethylenedioxy)-bis(ethylamine), respectively.

Pang et al. [64] suggested that the PL of C-dots is directly related to surface-state emission, but the energy gap is controlled not only by the nature of the surface, but also by the size of the carbogenic core. In particular, they reported the synthesis of Cdots via $\mathrm{HNO}_{3}$-assisted oxidation of carbon fibres (CFs). By means of ultrafiltration and using membranes with molecular cutoffs $<3 \mathrm{kDa}, 3-10 \mathrm{kDa}$ and $10-30 \mathrm{kDa}$, three different fractions were isolated with $\mathrm{d}_{\mathrm{av}}=2.7,3.3$ and $4.1 \mathrm{~nm}$, respectively. Evidently, low concentrations of $\mathrm{HNO}_{3}$ facilitate the commencement of exfoliation from the defect sites of $\mathrm{CFs}$, leading to small and blue-shifted C-dots. In contrast, higher concentrations of $\mathrm{HNO}_{3}$ and larger oxidation times give rise to larger, red-shifted C-dots with a higher degree of surface oxidation. By accurately controlling the oxidation conditions (reaction time, size of cutoff membranes, concentration of nitric acid), a series of well-defined C-dots were prepared that exhibited $\lambda_{\mathrm{ex}}$-independent emission, but their $\lambda_{\max }$ varied from $430 \mathrm{~nm}$ to $610 \mathrm{~nm}\left(\lambda_{\mathrm{ex}}=360 \mathrm{~nm}\right)$.

\subsubsection{Solvatochromism}

Solvatochromism effects are common in C-dot dispersions and have been attributed to extensive nanoparticle-solvent dipole-dipole interactions and H-bonding [65]. By virtue of their highly responsive nature, solvatochromic C-dots have been explored as sensitive optical sensors to detect volatile organic compounds [66]. Interestingly, emissive contributions arising from edge and surface bands might induce solvatochromic shifts in the opposite directions [67]. At the same time, pyrrolic nitrogen- and amino nitrogenenriched C-dots show wider solvatochromic shifts and impart higher QY [68].

Wang et al. [69] used p-PD and diphenyl ether as precursors to synthesize spherical C-dots with $d_{a v}=2.6 \mathrm{~nm}$. FT-IR revealed the presence of $-\mathrm{OH}, \mathrm{N}-\mathrm{H}, \mathrm{C}-\mathrm{H}, \mathrm{C}=\mathrm{N}, \mathrm{C}=\mathrm{C}, \mathrm{C}-\mathrm{N}$ and $\mathrm{C}-\mathrm{O}$ groups. $\mathrm{C} 1 \mathrm{~s}$ XPS indicated the presence of $\mathrm{C}-\mathrm{C} / \mathrm{C}=\mathrm{C}, \mathrm{C}-\mathrm{N}, \mathrm{C}-\mathrm{O}$ and $\mathrm{C}=\mathrm{N} ; \mathrm{N} 1 \mathrm{~s}$ XPS indicated the presence of pyridinic, amino and pyrrolic $\mathrm{N}$ and $\mathrm{O} 1 \mathrm{~s}$ XPS suggested the presence of $\mathrm{C}-\mathrm{O}$ bonds. When the $\mathrm{C}$-dots were dispersed in $\mathrm{CCl}_{4}$, toluene, $\mathrm{CHCl}_{3}$, acetone, DMF, $\mathrm{CH}_{3} \mathrm{OH}$ and $\mathrm{H}_{2} \mathrm{O}$, their $\lambda_{\max }$ was at $511,525,545,554,568,602$ and $615 \mathrm{~nm}$, respectively. In other words, the PL of C-dots systematically red-shifts as the polarity of the aprotic solvent increases. In protic solvents (such as methanol, ethanol, benzyl alcohol, 1-hexanol and 1-octanol), the C-dots emitted identical red PL regardless of the nature of the solvent, an effect that has been attributed to the formation of hydrogen bonds between the $\mathrm{N}$ and $\mathrm{O}$ atoms on the surface of $\mathrm{C}$-dots and the - $\mathrm{OH}$ groups of the solvent molecules, which stabilize the excited states.

In addition, $\mathrm{Li}$ et al. [70] followed thermal treatment of CA, DMF and urea to synthesize C-dots that showed enhanced red $\left(\lambda_{\max }=640 \mathrm{~nm}\right)$ and NIR $\left(\lambda_{\max }=760 \mathrm{~nm}\right)$ emission in aprotic solvents such as DMSO, DMF and N-methyl-2-pyrrolidone. However, in water, these $\mathrm{C}$-dots exhibited weaker signals in the red region and showed no NIR emission. This solvatochromic effect was ascribed to electron-acceptor groups $(\mathrm{S}=\mathrm{O} / \mathrm{C}=\mathrm{O})$ of the aprotic solvents attached to the outer layers and the edges of the C-dots. Yang et al. [71] synthesized triphenylphosphine $\left(\mathrm{P}(\mathrm{Ph})_{3}\right)$ functionalized C-dots (p-C-dots) with $\mathrm{d}_{\mathrm{av}}=4 \mathrm{~nm}$ and QY up to $58 \%$. It was observed that $\lambda_{\text {ex }}$ of p-C-dots systematically red-shifted from 431 to $641 \mathrm{~nm}$ upon increasing the dielectric constant $(\varepsilon)$ of the dispersion medium (Figure 7), an effect that has been attributed to the reduced electron-donating capacity of the $\mathrm{P}(\mathrm{Ph})_{3}$ groups in environments with increased polarity.

\subsection{Applications of Aqueous Dispersions of Red C-Dots}

\subsubsection{Bioimaging}

Red/NIR-emissive C-dots are considered to be ideal for bioimaging applications because they allow larger penetration depth without damaging the surrounding tissue. To that end, Liu et al. [72] suggested a rapid synthesis of red-emitting C-dots $\left(\lambda_{\max }=630 \mathrm{~nm}\right)$ with QY $=10.8 \%$ in water and $31.5 \%$ in ethanol $\left(\lambda_{\mathrm{ex}}=540 \mathrm{~nm}\right)$ using o-PD as a precursor 
in diluted $\mathrm{HNO}_{3}$ via a one-step hydrothermal procedure. The C-dots showed low level of toxicity against mice osteoblasts MC3T3-E1 and bone marrow stromal cells (BMSCs) (Figure 7a,d). The bright field and FL images $\left(\lambda_{\mathrm{ex}}=530 \mathrm{~nm}\right)$ of MC3T3-E1 and BMSCs incubated with C-dots at a concentration of $200 \mu \mathrm{g} / \mathrm{mL}$ for $24 \mathrm{~h}$ at $37^{\circ} \mathrm{C}$ are displayed in Figure $7 \mathrm{~b}, \mathrm{c}, \mathrm{e}, \mathrm{f}$, suggesting that $\mathrm{C}$-dots are predominantly distributed into the cytoplasm and not the nucleus, thus facilitating high resolution cell imaging without affecting the replication or the transcription of DNA.

Tan et al. [73] followed electrochemical exfoliation of graphite in $0.01 \mathrm{M} \mathrm{K}_{2} \mathrm{~S}_{2} \mathrm{O}_{8}$ solution to synthesize red C-dots with $\mathrm{d}_{\mathrm{av}}=3 \mathrm{~nm}$ and $\lambda_{\max }=610 \mathrm{~nm}$ at $\lambda_{\mathrm{ex}}=500 \mathrm{~nm}$. Those C-dots, when used without any further surface treatment, showed minimal toxicity against HeLa cells and were able to stain both their cell membranes and their cytoplasm, offering clear images under an FL microscope while exhibiting excellent photostability over a prolonged period.

(a)

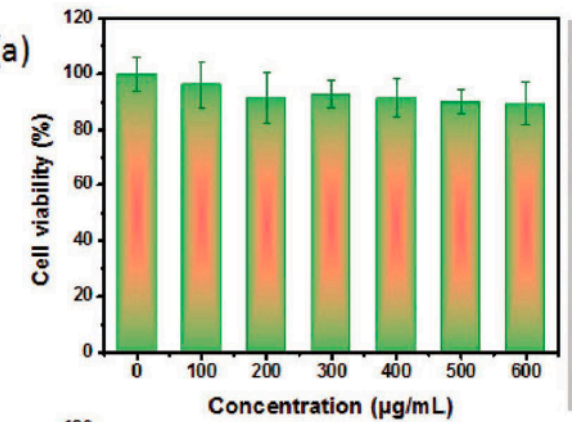

(d)

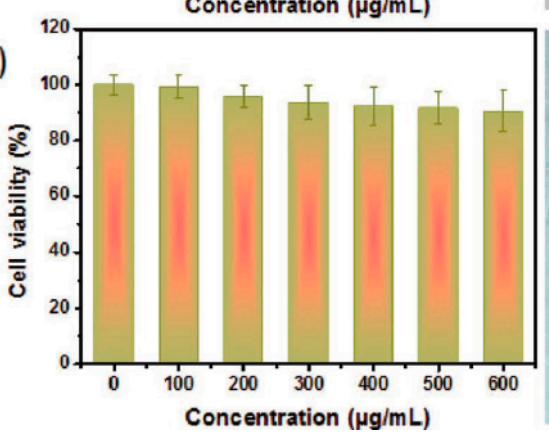

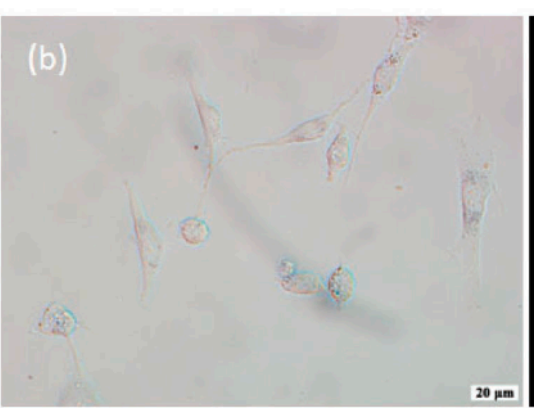
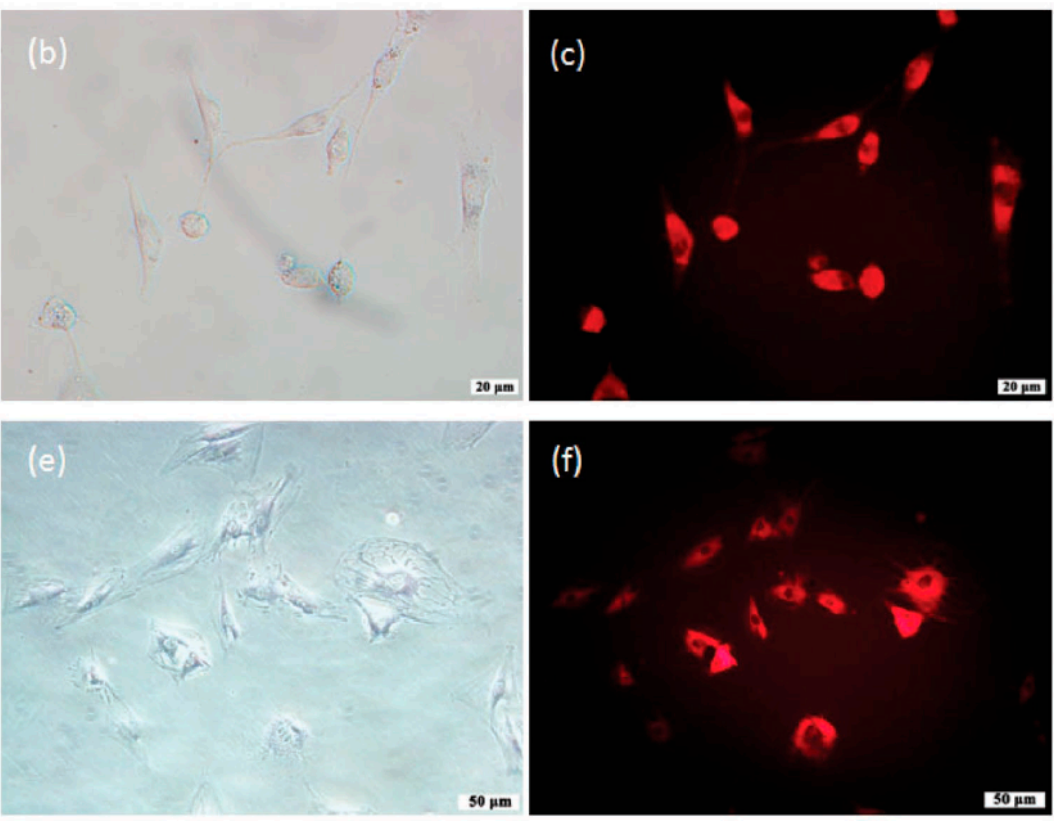

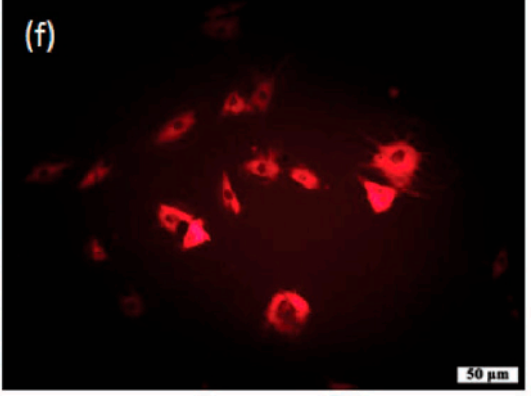

Figure 7. Viability of MC3T3-E1 (a) and BMSCs cells (d) after incubation with C-dots for a 24 h uptake process. FL images of $(\mathbf{b}, \mathbf{c})$ MC3T3-E1 and (e,f) BMSCs, respectively; $(\mathbf{b}, \mathbf{e})$ bright field and $(\mathbf{e}, \mathbf{f})$ under $\lambda_{\mathrm{ex}}=530 \mathrm{~nm}$. Reprinted (adapted) with permission from [72]. Copyright 2021 John Wiley and Sons.

\subsubsection{Sensing/Biosensing}

Oftentimes, heteroatom doping is coupled with surface patterning strategies and $\mathrm{sp}^{2}$ domain engineering in order to optimize red-shifted emissions. Along those lines, $\mathrm{Li}$ et al. [74] followed hydrothermal treatment of CA and thiourea to synthesize redemitting S,N codoped C-dots that were functionalized with phenylboronic acid tags yielding S,N-C-dots-PBA with QY $=23 \%$ and $\lambda_{\max }=593 \mathrm{~nm}$ under $\lambda_{\mathrm{ex}}=550 \mathrm{~nm}$. The S,N-C-dots-PBA showed excellent biocompatibility and were able to illuminate PC12 cells under the FL microscope 20 min after their injection (Figure 8a). Interestingly, the PL intensity decreased upon the addition of 1.0 and $5.0 \mu \mathrm{M} \mathrm{Fe}^{3+}$ (Figure $8 \mathrm{~b}, \mathrm{c}$ ), and the corresponding intracellular PL was compared to the S,N-C-dot-free sample (control) (Figure 8d). The quenching efficiency was $73 \%$ and $96 \%$ for $1.0 \mu \mathrm{M}$ and $5.0 \mu \mathrm{M} \mathrm{Fe}^{3+}$ ions, respectively. This behaviour indicates that S,N-C-dots-PBA can be explored for the highly sensitive intracellular detection of $\mathrm{Fe}^{3+}$. 

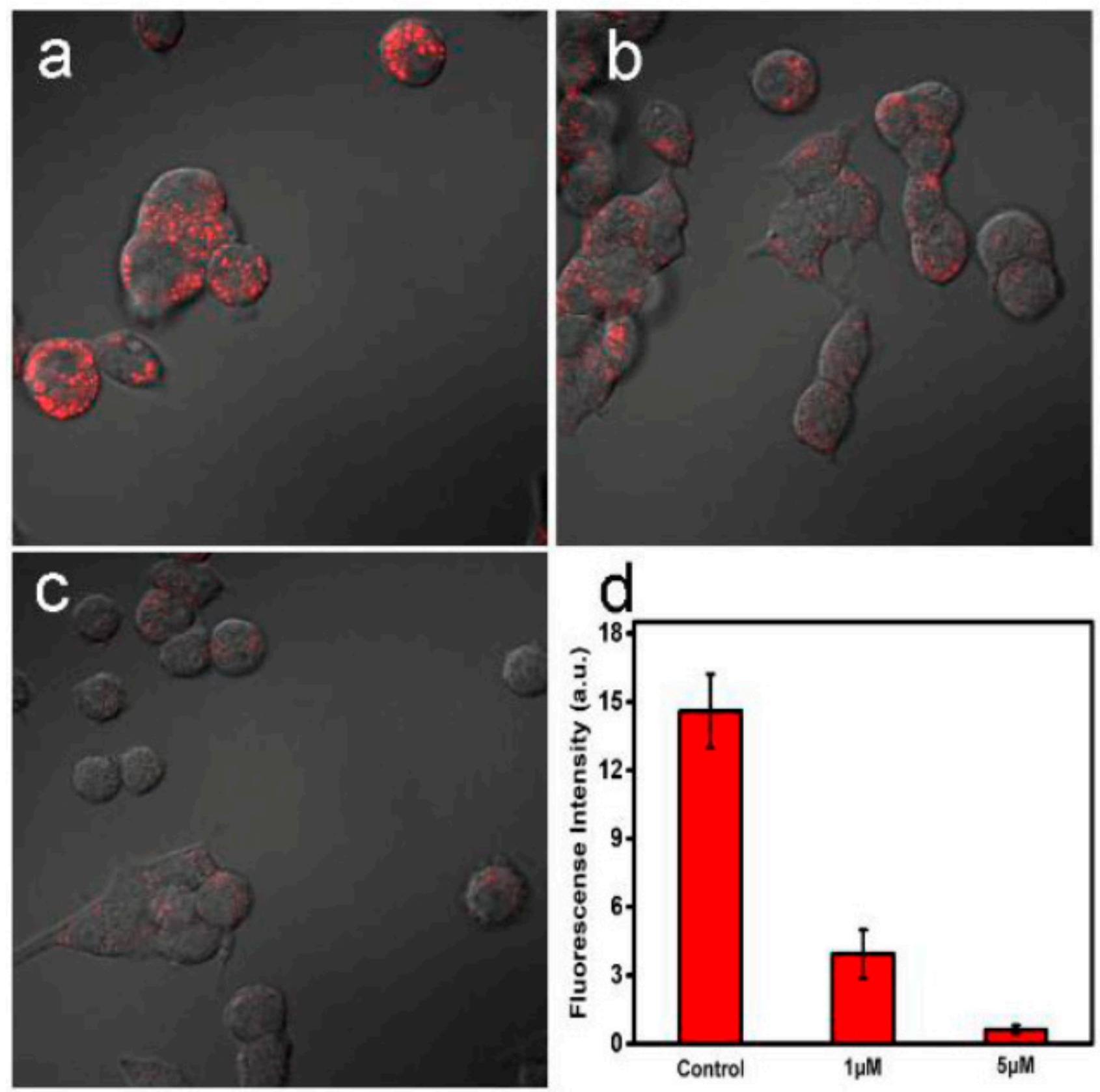

Figure 8. FL images of living PC12 cells stained with $5.0 \mu \mathrm{M} \mathrm{S,N-C-dots:} \mathrm{(a)} \mathrm{in} \mathrm{the} \mathrm{absence} \mathrm{of} \mathrm{Fe} \mathrm{F}^{3+}$ (control sample), (b) in the presence of $1.0 \mu \mathrm{M} \mathrm{Fe}^{3+}$, (c) in the presence of $5.0 \mu \mathrm{M} \mathrm{Fe}^{3+}$. (d) The PL intensity of samples described in (a-c). Reprinted (adapted) with permission from [74]. Copyright 2021 Elsevier.

In addition, Gao et al. [75] followed hydrothermal treatment of CA and neutral red dye (NR) (ratio of 1000:1) to prepare red-emissive C-dots, the PL of which quenched in the presence of $\mathrm{Pt}^{2+}$ (ethanol as solvent) due to a rapid electron-transfer process between the metal ions and the C-dots' surface. Moreover, zebrafish (ZF) that were loaded with $\mathrm{Pt}^{2+}$ and C-dots exhibited PL properties in a manner that critically depended on the concentration of the internalized $\mathrm{Pt}^{2+}$ (Figure 9), indicating that C-dots can be used as sensors to quantify the $\mathrm{Pt}^{2+}$ levels present in living organisms. 

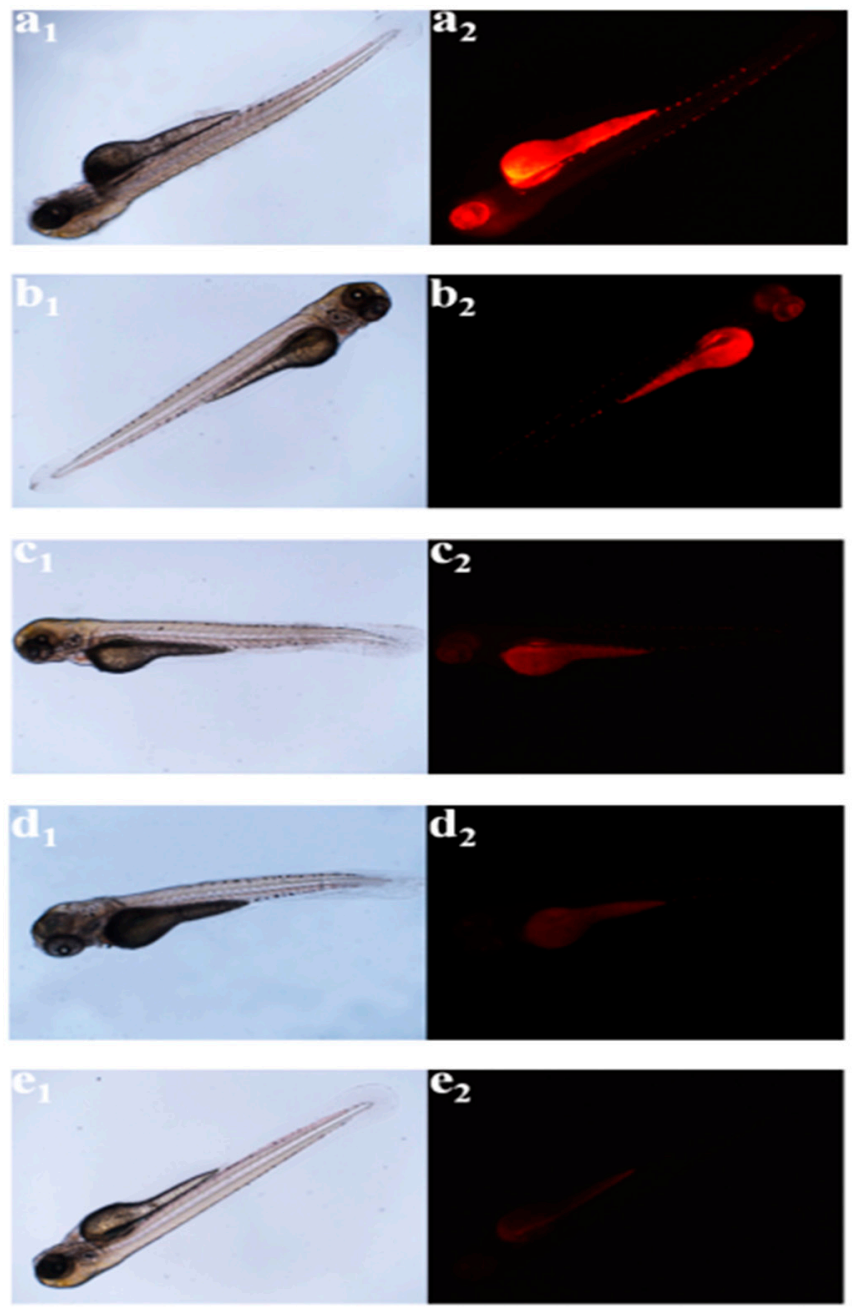

Figure 9. FL imaging of $\mathrm{Pt}^{2+}$ in $\mathrm{ZF}:\left(\mathbf{a}_{1}-\mathbf{e}_{1}\right)$ Optical images and $\left(\mathbf{a}_{2}-\mathbf{e}_{2}\right)$ FL images stemming from C-dots in ZF loaded with several concentrations of $\mathrm{Pt}^{2+}: 0\left(\mathbf{a}_{1}, \mathbf{a}_{2}\right) ; 30\left(\mathbf{b}_{1}, \mathbf{b}_{2}\right) ; 60\left(\mathbf{c}_{\mathbf{1}}, \mathbf{c}_{\mathbf{2}}\right) ; 100\left(\mathbf{d}_{\mathbf{1}}, \mathbf{d}_{\mathbf{2}}\right)$ and $150 \mu \mathrm{M}\left(\mathbf{e}_{1}, \mathbf{e}_{2}\right)$. Reprinted (adapted) with permission from [75]. Copyright 2021 American Chemical Society.

\subsubsection{Photothermal Therapy (PTT)}

Photothermal therapy (PTT) relies on radiation-absorbing particles to cause thermal ablation of tumour cells and subsequent cell death. Red-shifted C-dots are ideal candidates as PTT agents due to their low phototoxicity, great photothermal conversion effectiveness and deep tissue penetration.

As mentioned in the Heteroatom doping section, Ge et al. [47] developed a hydrothermal approach of PPA to fabricate red-emissive C-dots (u-C-dots) that showed a wide absorption range from 400 to $750 \mathrm{~nm}$ and $38.5 \%$ photothermal conversion. Those properties make $\mathrm{u}$-C-dots suitable for PL and photoacoustic (PA) imaging as well as PPT. In Figure 10a IR images of a mouse that was subjected to intertumoral injection of $\mathrm{u}$-C-dots indicate that the temperature of the tumour cells rose up to $58.4{ }^{\circ} \mathrm{C}$ within $10 \mathrm{~min}$ of laser radiation, thus causing permanent damage to cancer cells. Following a 16-day course, the tumour disappeared and the mouse fully recovered, while the mouse receiving saline treatment failed to do so (Figure 10b,c). At the same time, no distinct inflammation, cell necrosis or apoptosis in the heart, liver, spleen, lung or kidney were observed, confirming the absence of undesired side effects induced by $\mathrm{u}$-C-dots (Figure 10d). 
(a)

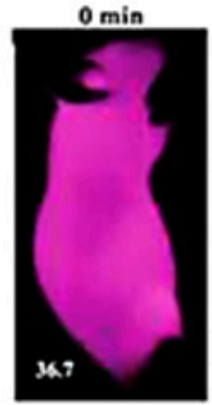

(b)

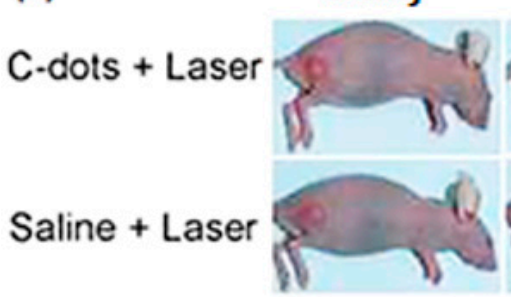

(d)

Control
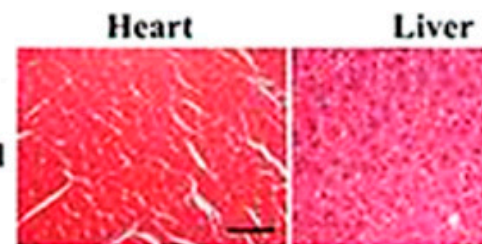

$3 \mathrm{~min}$

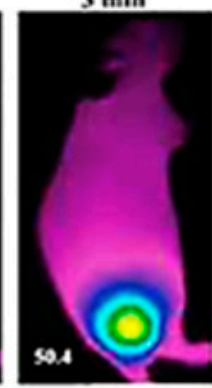

16 days
$1 \mathrm{~min}$

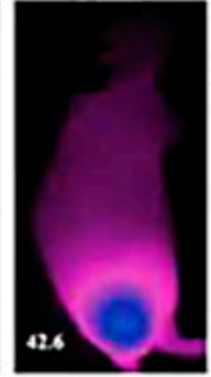

6 days
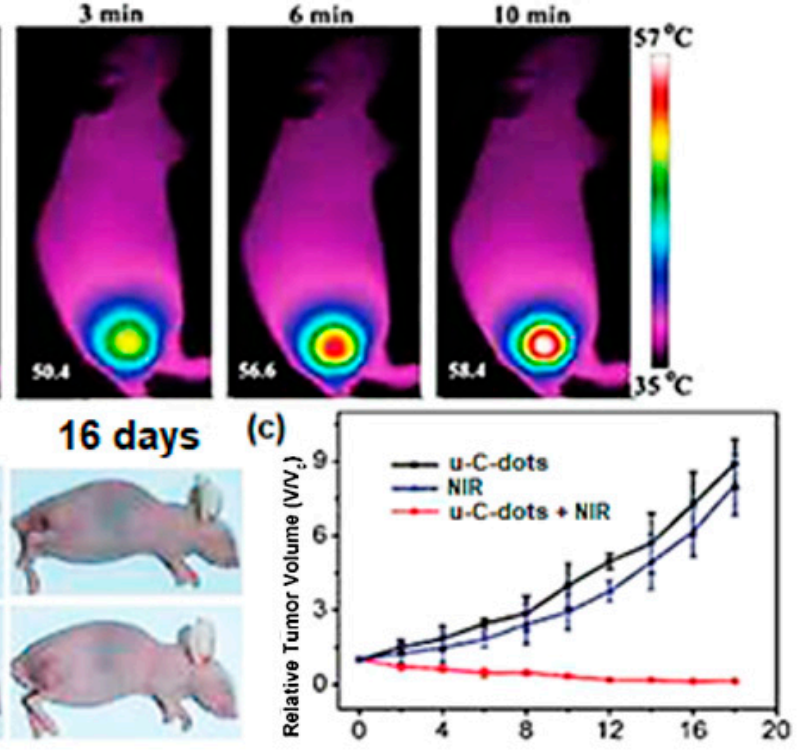

Splecn

Kidncy

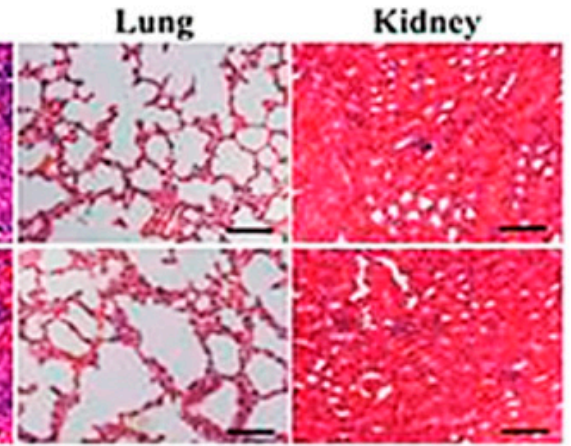

Figure 10. (a) IR images of $\mathrm{u}-\mathrm{C}$-dots injected into mice tumour locations under laser irradiation $\left(671 \mathrm{~nm}\right.$ at $\left.2 \mathrm{~W} / \mathrm{cm}^{2}\right)$; (b) photos of the mice tumours on several days after the two treatments; (c) relative change in the tumour volume over time during the treatments utilizing only u-C-dots, only NIR irradiation and their combination; (d) haematoxylin- and eosin-stained slices of the heart, liver, spleen, lung and kidney in mice after PTT. Scale bar is $50 \mu$ m. Reprinted (adapted) with permission from [47]. Copyright 2021 John Wiley and Sons.

\subsubsection{Photodynamic Therapy (PDT)}

Photodynamic therapy (PDT) has distinct advantages over traditional cancer treatments (surgery, chemotherapy and radiotherapy) such as low toxicity, minimal damage to healthy tissue and mild side effects. In PDT, a laser beam excites the photosensitizer to generate reactive oxygen that eventually destroys the tumour cells.

Jia's group [76] followed solvothermal treatment of Hypocrella Bambusae to synthesize red-emissive HBC-dots with $\mathrm{d}_{\mathrm{av}}=4.8 \mathrm{~nm}$ and $\lambda_{\max }=610 \mathrm{~nm}$ at $\lambda_{\mathrm{ex}}=540 \mathrm{~nm}$. After $10 \mathrm{~min}$ of laser irradiation $\left(635 \mathrm{~nm}\right.$ at $\left.0.8 \mathrm{~W} / \mathrm{cm}^{2}\right)$, the temperature of the $\mathrm{HBC}$-dot solution $(200 \mu \mathrm{g} / \mathrm{mL})$ rose by $26.9^{\circ} \mathrm{C}$, while it increased by only $3.7^{\circ} \mathrm{C}$ upon irradiation at $0.1 \mathrm{~W} / \mathrm{cm}^{2}$. The results confirmed that the $\mathrm{HBC}$-dots, at $0.1 \mathrm{~W} / \mathrm{cm}^{2}$, could produce ${ }^{1} \mathrm{O}_{2}$, facilitating PDT, but at $8 \mathrm{~W} / \mathrm{cm}^{2}$ they could generate both ${ }^{1} \mathrm{O}_{2}$ and thermal energy, facilitating both PDT and PTT treatments. Upon a 6-hour incubation of HeLa cells with HBC-dots, it was observed that the cytoplasm emitted red PL (Figure 11a). The coincubation of HeLa cells with HBC-dots and $2^{\prime}, 7^{\prime}$-Dichlorofluorescin diacetate (DCF-DA), a green dye that is commonly used to probe intracellular ${ }^{1} \mathrm{O}_{2}$ formation, followed by $635 \mathrm{~nm}$ irradiation gave rise to strong green PL emission (Figure 11b), thus confirming the presence of ${ }^{1} \mathrm{O}_{2}$. Moreover, standard MTT assay showed that HBC-dots exhibited low toxicity against HeLa cell under dark conditions (black bars in Figure 11c). The cell viability was compromised at power density at $0.1 \mathrm{~W} / \mathrm{cm}^{2}$ (PDT system, red bars in Figure 11c), and the effect was more pronounced at power density at $0.8 \mathrm{~W} / \mathrm{cm}^{2}$ (PDT+PTT system, blue bars in Figure 11c), 
given that $99 \%$ of HeLa cells incubated with $200 \mathrm{mg} / \mathrm{mL}$ HBC-dots did not survive. After intravenous injection of HBC-dots in mice, the PL intensity in cancer sites rose with time, reaching its maximum value after $8 \mathrm{~h}$ (Figure $11 \mathrm{~d}$ ).

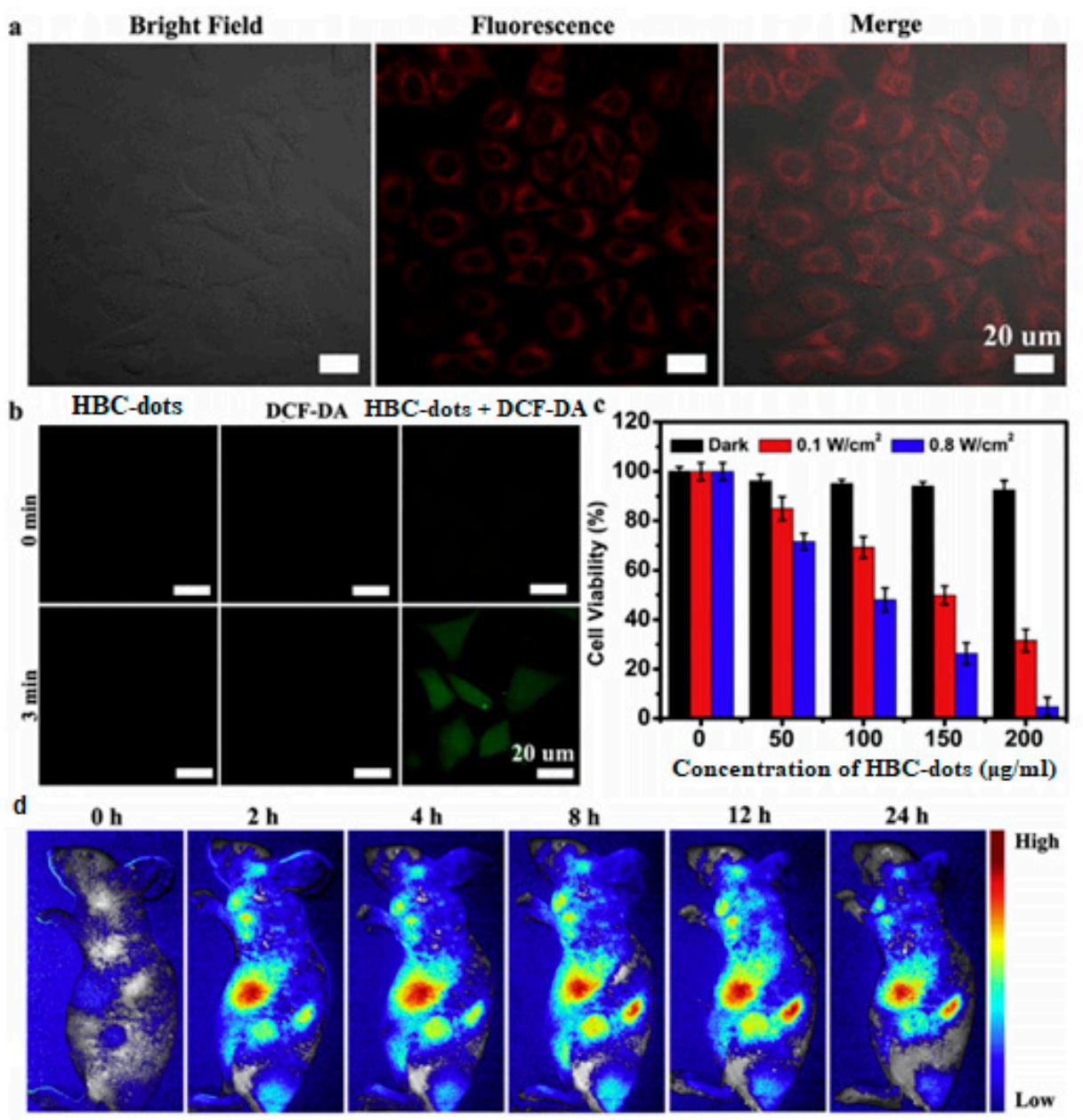

Figure 11. (a) FL images of HeLa cells incubated with HBC-dots. (b) FL imaging of HeLa cells stained with HBC-dots, DCF-DA and their combination. (c) Viability of HeLa cells incubated with HBC-dots after several treatments. (d) In vivo FL images of mice after intravenous injection of HBC-dots in PBS. Reprinted (adapted) with permission from [76]. Copyright 2021 Elsevier.

Ge et al. [77] synthesized C-dots with excellent water solubility using polythiophene derivatives as the precursor via a hydrothermal method. The C-dots showed interesting properties such as a broad absorption region from the visible to the NIR, superior biocompatibility and photostability, high ${ }^{1} \mathrm{O}_{2}$ yield and strong emission with $\lambda_{\max }=680 \mathrm{~nm}$ at $\lambda_{\mathrm{ex}}=488 \mathrm{~nm}$.

\subsection{Solid-State Red C-Dots and Their Applications}

Significant progress has been made in solid-state red C-dot-based systems such as hybrid powders and polymer nanocomposites typically derived via in situ polymerization, mechanical and melt mixing and solution blending.

\subsubsection{WLEDs (White Light-Emitting Diodes)}

Yuan et al. [78] fabricated graphitic, excitation-independent, green-emitting GnCdots $\left(\mathrm{d}_{\mathrm{av}}=6.5 \mathrm{~nm}, \lambda_{\max }=515 \mathrm{~nm}, \lambda_{\mathrm{ex}}=460 \mathrm{~nm}, \mathrm{QY}=81 \%\right)$ following solvothermal treatment of perylene that were further treated with $\mathrm{NaOH}$ to produce red-emitting $\mathrm{RdC}$ dots $\left(\mathrm{d}_{\mathrm{av}}=6.45 \mathrm{~nm}, \lambda_{\max }=610 \mathrm{~nm}\right.$, at $\left.\lambda_{\mathrm{ex}}=560 \mathrm{~nm}, \mathrm{QY}=80 \%\right)$, as shown in Figure 12a,b. 
FT-IR proved the presence of $-\mathrm{NO}_{2}$ and $-\mathrm{NH}_{2}$ for the $\mathrm{GnC}$-dots and the $\mathrm{C}=\mathrm{O}$ in the quinone structure for the $\mathrm{RdC}$-dots. The dispersion of $\mathrm{GnC}$-dots into methyltriethoxysilane (MTES) and RdC-dots into 3-triethoxysilylpropylamine (APTES) gave rise to transparent nanocomposite gel glasses that under UV radiation appeared green and red, respectively (Figure 12c). To form WLEDs, the GnC-dots/MTES gel was deposited (and allowed to dry) on a blue LED chip ( $27 \mathrm{~lm} / \mathrm{W}$ at $\left.20 \mathrm{~mA}, \lambda_{\mathrm{ex}}=460 \mathrm{~nm}\right)$, followed by the deposition of RdC-dots / APTES gel (Figure 12d). The electroluminescence (EL) spectra of both cold and warm WLED lamps revealed three emission peaks located at 460, 508 and $615 \mathrm{~nm}$, corresponding to the emissions of the LED chip, GnC-dots and RdC-dots (Figure 12e), respectively. Moreover, the warm WLED lamp showed a high colour rendering index (CRI) of 92.9 , compared to CRI $=81.1$ for the cold lamp.
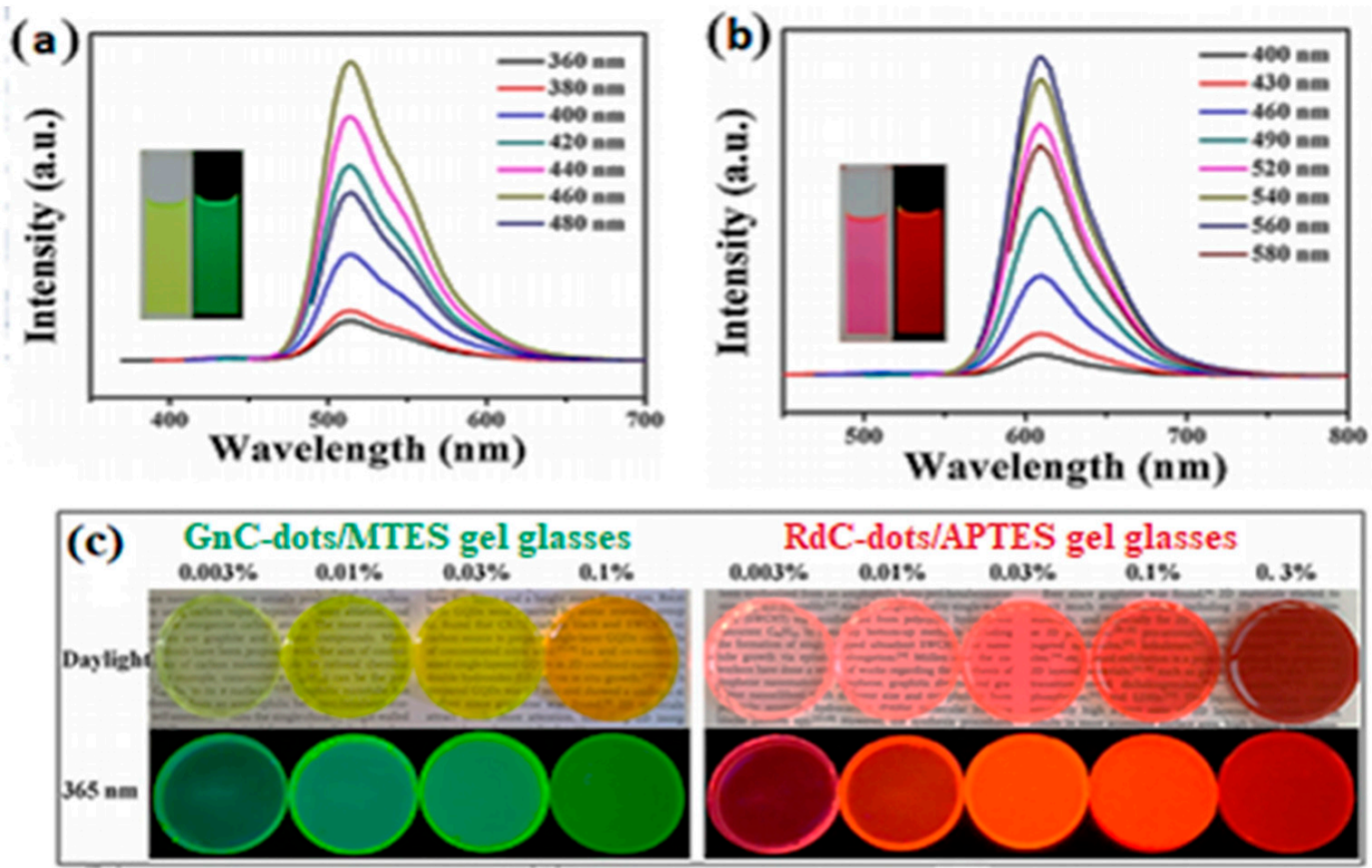

(d)

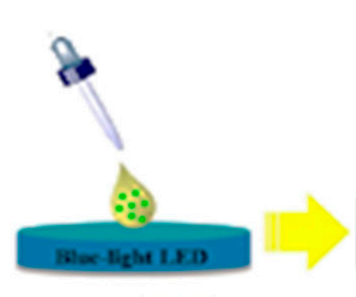

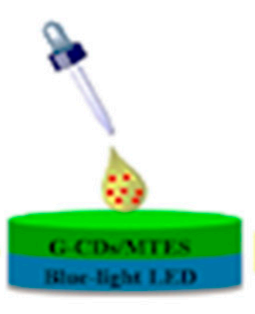

(e)

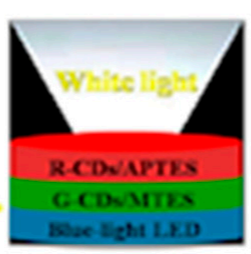

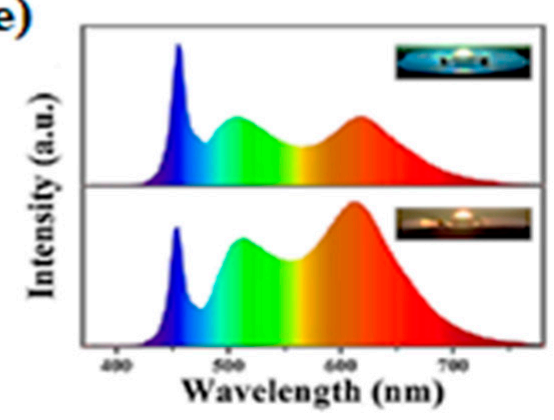

Figure 12. PL spectra of (a) GnC-dots and (b) RdC-dots under different $\lambda_{\mathrm{ex}}$ (inset: images under daylight (left) and $365 \mathrm{~nm}$ light (right)). (c) Photographs of GnC-dot/MTES and RdC-dot/APTES gels bearing various C-dot loadings under daylight (up) and $365 \mathrm{~nm}$ excitation (down). (d) Fabrication of WLEDs from GnC-dot/MTES and RdC-dot/APTES gel glasses. (e) EL spectra (up: cold WLED, down: warm LED and insets: the picture below WLED). Reprinted (adapted) with permission from [78]. Copyright 2021 American Chemical Society.

Jin et al. [79] followed hydrothermal treatment of a l-tyrosine, o-PD, l-tyrosine/o-PD mixture to generate blue $\left(\mathrm{d}_{\mathrm{av}}=5.1 \mathrm{~nm}, \mathrm{QY}=8.6 \%\right.$ at $\left.\lambda_{\mathrm{ex}}=365 \mathrm{~nm}\right)$, green $\left(\mathrm{d}_{\mathrm{av}}=5.7 \mathrm{~nm}\right.$, 
$\mathrm{QY}=12.6 \%$ at $\left.\lambda_{\mathrm{ex}}=430 \mathrm{~nm}\right)$ and orange $/ \mathrm{red} C$-dots $\left(\mathrm{d}_{\mathrm{av}}=4.4 \mathrm{~nm}, 20.9 \%\right.$ at $\left.\lambda_{\mathrm{ex}}=405 \mathrm{~nm}\right)$. Subsequently, the C-dots were dispersed in polyvinyl alcohol (PVA) to generate blue-, green- and orange/red- emissive films. The films were deposited on a UV chip to generate WLED with Commission Internationale de L'Eclairage (CIE) chromaticity coordinates (0.30, $0.33)$, compared to pure white light $(0.33,0.33)$.

As aforementioned, Wang et al. [69] followed a solvothermal treatment of p-PD into diphenyl ether to synthesize graphitic $C$-dots that exhibited $\lambda_{\max }$ at 511, 525, 545, 554, 568, 602 and $615 \mathrm{~nm}$ in $\mathrm{CCl}_{4}$, toluene, $\mathrm{CHCl}_{3}$, acetone, $\mathrm{DMF}, \mathrm{CH}_{3} \mathrm{OH}$ and $\mathrm{H}_{2} \mathrm{O}$, respectively. To prepare liquid LEDs, $\mathrm{C}$-dot dispersions in toluene, DMF and methanol were encapsulated in silica glass boxes and packed above a UV-LED chip $\left(\lambda_{\mathrm{em}}=370 \mathrm{~nm}\right)$ in order to generate green, yellow and red PL contributions respectively. Moreover, the green-emissive C-dots in methyl methacrylate nanocomposite and the red-emissive C-dots in PVA nanocomposite were deposited on a UV-LED chip to assemble solid LEDs.

Zhang et al. [80] synthesized a colour-tuneable solid-state luminescent material via a hydrothermal procedure using CA, urea and Eu (DPA) 3 and a 2D-layered-structure nanoclay. The hybrid material obtained showed tuneable emission colours from red to blue under different $\lambda_{\mathrm{ex}}$, where the $\mathrm{Eu}^{3+}$ and C-dots mainly contributed to the red and blue emission, respectively, making them potential candidates for WLED applications. Yuan et al. [81] synthesized amorphous, red-emissive C-dots using 1,2,4-triaminobenzen as carbon source and PEG200 as passivation agent via a solvothermal method. The C-dots showed $\lambda_{\text {ex }}{ }^{-}$ independent behaviour, with a QY up to $25 \%$ in ethyl acetate $\left(\lambda_{\text {ex }}=460 \mathrm{~nm}\right)$, and were combined with silica to fabricate red PL powder in order to construct warm WLEDs.

\subsubsection{Pollutant Sensing}

Liang's group [82] followed the carbonization of sugarcane bagasse in a mixture of concentrated sulfuric and phosphoric acid to synthesize red-emitting C-dots that were subsequently coated on polyvinylidene fluoride (PVDF) membranes. The PVDF/C-dot membranes exhibited red PL $\left(\lambda_{\mathrm{ex}}=365 \mathrm{~nm}\right)$ that was quenched in the presence of ammonia, but not in the presence of acetonitrile, o-nitrotoluene, toluene, cyclohexylamine, hydrazine, ethanediamine, dimethyl sulfoxide, acetic acid, acetone, chloroform or hydrochloric acid (Figure 13a,b). The PVDF/C-dot system was shown to be a highly selective and highly sensitive sensor for ammonia with a detection limit of $1.7 \mathrm{ppm}$ and a response time of $30 \mathrm{~s}$ (Figure 13c).
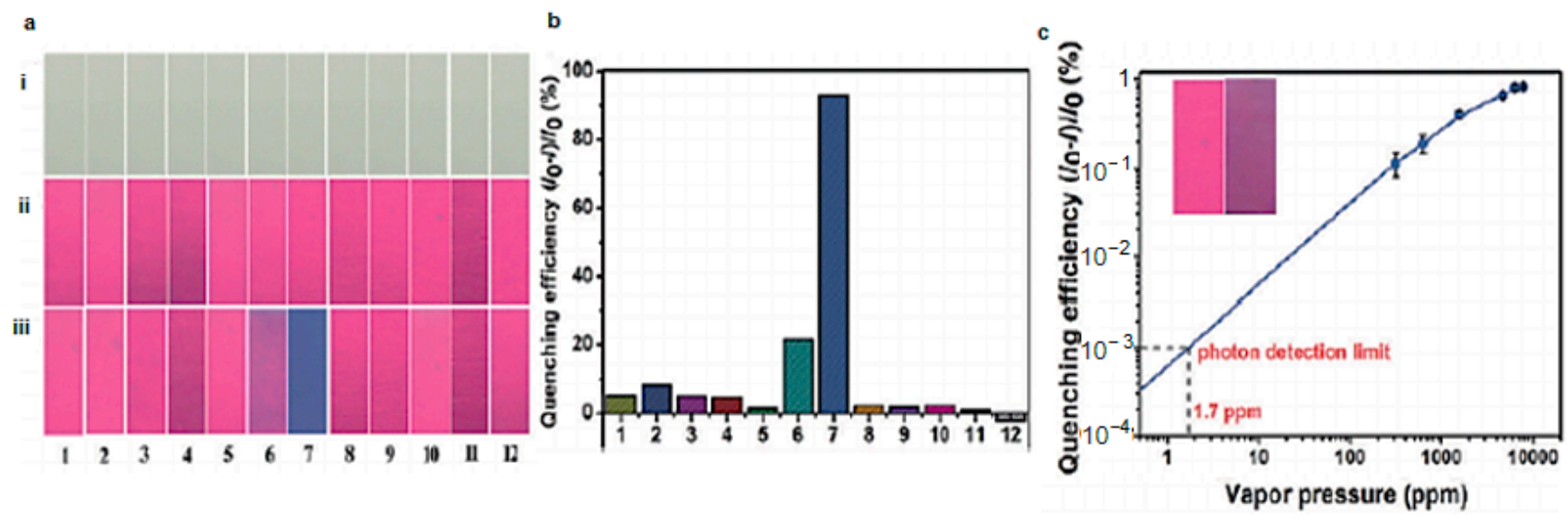

Figure 13. (a) Images of PVDF/C-dot membranes under visible light (i) and before (ii) and after (iii) exposure to saturated vapours of various solvents with a response time of $30 \mathrm{~s}\left(\lambda_{\mathrm{ex}}=365 \mathrm{~nm}\right): 1$, acetonitrile; 2, o-nitrotoluene; 3, toluene; 4, cyclohexylamine; 5 , hydrazine; 6 , ethanediamine; 7 , ammonia; 8 , dimethyl sulfoxide; 9 , acetic acid; 10 , acetone; 11 , chloroform; 12 , hydrochloric acid. (b) Quenching efficiency in the presence of molecules 1-12. (c) Quenching efficiency as a function of vapour pressure of ammonia. Inset: Images of the PVDF/C-dots before (left) and after (right) exposure to 310 ppm of ammonia with a response time $30 \mathrm{sec}\left(\lambda_{\mathrm{ex}}=365 \mathrm{~nm}\right)$. Reprinted (adapted) with permission from [82]. Copyright $2021 \mathrm{John}$ Wiley and Sons. 
Lu et al. [83] followed hydrothermal treatment of citric acid and ethylenediamine in formamide-water binary systems to generate a mixture of blue and red-emissive C-dots. Subsequently, ion imprinted mesoporous polymers were prepared using $\mathrm{Cr}^{3+}$ and $\mathrm{Pb}^{2+}$ as templates and the mixture of blue and red C-dots as fluorescent probes to generate a dual channel detection system, given that $\mathrm{Cr}^{3+}$ only quenches the emission of blue Cdots and $\mathrm{Pb}^{2+}$ only quenches red $\mathrm{C}$-dots. The detection limits for $\mathrm{Cr}^{3+}$ and $\mathrm{Pb}^{2+}$ were $27 \mathrm{~nm}$ and $34 \mathrm{~nm}$, respectively. Hu et al. [84] followed a solvothermal treatment of ophenylenediamine and selenourea in $\mathrm{HCl}$ to synthesize red-emissive $\mathrm{Se}, \mathrm{N}, \mathrm{Cl}$ codoped C-dots with $Q Y=23.6 \%$, the emission of which can be selectively quenched in the presence of malachite green (MG), thus functioning as nanosensors for MG with a limit of detection close to $20 \mathrm{nM}$.

\subsubsection{Nanoforensics}

Li et al. [85] synthesized red-emissive, $\lambda_{\mathrm{ex}}$-independent, graphitic C-dots (pC-dots) with $\mathrm{d}_{\mathrm{av}}=12.5 \mathrm{~nm}$ following solvothermal treatment of $\mathrm{p}$-PD. FT-IR of $\mathrm{pC}$-dots showed the stretching vibrations of $\mathrm{N}-\mathrm{H}, \mathrm{C}=\mathrm{N}, \mathrm{C}=\mathrm{C}$ and $\mathrm{C}=\mathrm{C}$, and XPS spectra revealed they consisted of $\mathrm{C}(79.56 \%), \mathrm{N}(15.61 \%)$ and $\mathrm{O}(4.83 \%)$. As shown in Figure 14a, incorporation of pC-dots into starch gave rise to highly PL powders (the PL spectra of pC-dots in ethanol is also displayed for comparison). The $\mathrm{pC}$-dot/starch powder was used to develop latent fingerprints deposited on a glass substrate and was able to reveal well-defined ridges with minimal background interference (Figure 14b).

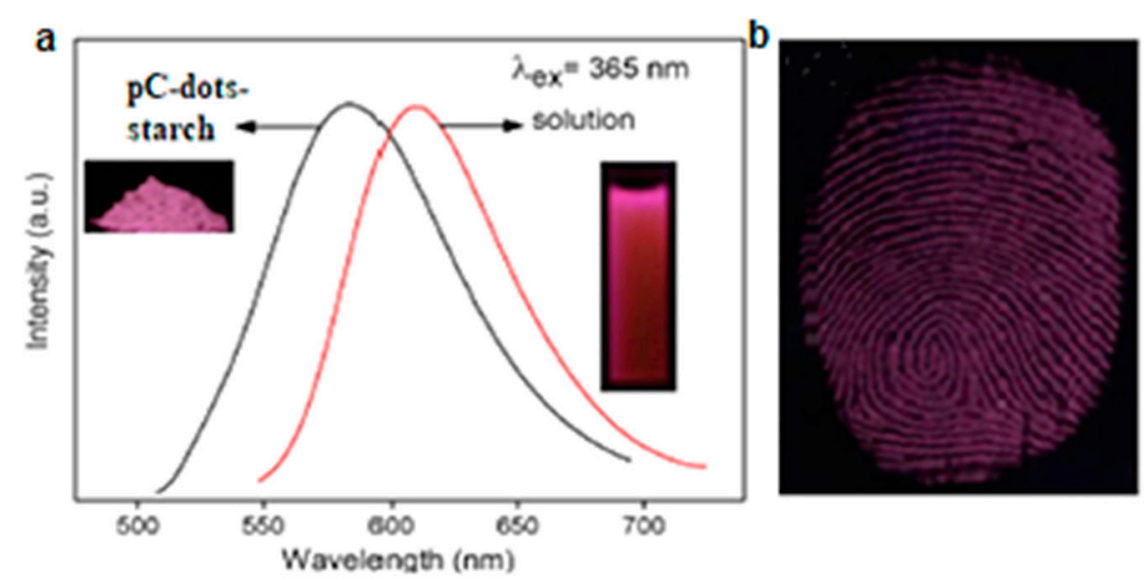

Figure 14. (a) PL emission spectra of $\mathrm{pC}$-dots in ethanol and $\mathrm{pC}$-dot starch powder. Inset: pC-dots in ethanol solution (right) and pC-dot starch powder (left) $\left(\lambda_{\mathrm{ex}}=365 \mathrm{~nm}\right)$. (b) Image of fingerprints developed with pC-dot starch on glass substrate $\left(\lambda_{\mathrm{ex}}=365 \mathrm{~nm}\right)$. Reprinted (adapted) with permission from [83]. Copyright 2021 Elsevier.

Yuan et al. [86] followed a solvothermal treatment of o-phenylenediamine and 1,8diamino naphthalene in DMF in the presence of boric acid to synthesize red-emissive B-doped C-dots with QY $=12 \%$. The B-C-dot dispersion in PVA was used as an ink for advanced anticounterfeit applications, given that it appears blue upon UV excitation but becomes pink after alkali treatment and returns to blue after acid treatment in a reversible manner.

\section{Conclusions}

Although the large-scale production of well-defined, red-emissive C-dots remains an open challenge, a number of promising approaches towards this direction have been demonstrated. These synthetic strategies rely on heteroatom doping, surface functionalization and the formation of extensively conjugated domains, while a combination of two or more of those engineering principles is usually more effective in terms of PL performance. In contrast to their blue and green counterparts, the synthesis of red C-dot-based systems is 
rather tedious and energy intensive and largely depends on the use of aromatic precursors, organic solvents and toxic compounds. Overcoming those barriers will allow the development of a new generation of photoactive materials that can potentially advance crucial biomedical treatments, sensing applications and lighting technologies.

\section{Outlook}

There is no doubt that C-dots are a highly promising class of nanomaterials with distinct advantages with respect to conventional organic fluorescent dyes because of their multicolour nature and enhanced structural stability, while they are superior in terms of environmental friendliness and preparation ease compared to heavy metal-based quantum dots. These nanoemitters can be used in isolation for a variety of applications [38] or can be combined with other materials to generate advanced nanocomposites and devices, such as polymeric hybrids [27], powder compositions [87], ordered mesoporous frameworks [88] and C-dot-based Forster resonance energy transfer systems [89]. At the same time, their photoluminescence mechanism is not fully understood, and more studies are needed in order to gain further insights on the structure-properties relationships of those complex systems. This observation is particularly true for red-emissive C-dots, which are only recently gaining significant attention from the scientific community, although both challenges and benefits associated with their production are well-recognized.

First is the observation that the majority of C-dots typically display weak emissions on the red end of the spectrum, while certain approaches allow the synthesis of predominantly red nanoemitters. A recent theoretical study indicated that improved red emission is expected for C-dots bearing abundant weakly interacting surface emission centres [90]. Simple post-modification treatments (such as the reaction with acetaldehyde [91]) can modulate the PL emission, essentially converting blue-emitting into red-emitting C-dots. In addition, C-dots with reversibly switchable green-red emissions have been reported $[78,86]$.

Second is the realization that a number of effective strategies for the large-scale production of blue and green $C$-dots that require a relatively low capital investment are emerging in the literature, but those efforts are less advanced for their red-emissive counterparts. Nevertheless, cost-effective approaches that are compatible with standard industrial processing are present in the literature. For example, far-red C-dots with QY $=18.5 \%$ were prepared via a 3 min microwave treatment of glutathione in formamide followed by centrifugation and dialysis [92]. Moreover, red C-dots with QY $=53 \%$ can be produced on a gram scale by heating a formamide solution of citric acid and ethylenediamine [93].

Third is the understanding that the nature of the precursor material plays a significant role on the PL properties of the red-emissive C-dots. For example, red C-dots with QY $=84 \%$ are derived from the highly conjugated molecular precursor tris(4-aminophenyl)amine [94]. In analogy to blue and green C-dots, organic fluorophores developed in situ during the synthesis of red C-dots are expected to have a pronounced impact on their PL properties. We note that it has been suggested that red emission might be associated exclusively to organic fluorophores entrapped within the carbogenic structure [37]. In terms of biomass utilization, we note that red-emitting $\mathrm{N}, \mathrm{Mg}$ codoped C-dots from the leaves extract of Bougainvillea plant showed $\lambda_{\text {ex }}$-independent emissions with $\lambda_{\max }=678 \mathrm{~nm}$ and QY $=40 \%$ [95], while NIR-C-dots with QY $=31 \%$ and $15.3 \%$ were synthesized by heating a formamide solution of lemon juice [40] and via solvothermal treatment of spinach [96].

Author Contributions: Conceptualization, S.G. and A.K.; writing, S.G. and A.K. Both authors have read and agreed to the published version of the manuscript.

Funding: S.G. was supported by the University Alliance Doctoral Training Alliance under the Marie Skłodowska-Curie COFUND scheme.

Conflicts of Interest: The authors declare no conflict of interest. 


\section{References}

1. Baker, S.N.; Baker, G.A. Luminescent carbon nanodots: Emergent nanolights. Angew. Chem. Int. Ed. 2010, 49, 6726-6744. [CrossRef] [PubMed]

2. Li, H.; Kang, Z.; Liu, Y.; Lee, S.-T. Carbon nanodots: Synthesis, properties and applications. J. Mater. Chem. 2012, 22, 24230-24253. [CrossRef]

3. Lim, S.Y.; Shen, W.; Gao, Z. Carbon quantum dots and their applications. Chem. Soc. Rev. 2014, 44, 362-381. [CrossRef] [PubMed]

4. Yuan, F.; Li, S.; Fan, Z.; Meng, X.; Fan, L.; Yang, S. Shining carbon dots: Synthesis and biomedical and optoelectronic applications. Nano Today 2016, 11, 565-586. [CrossRef]

5. Sciortino, A.; Cannizzo, A.; Messina, F. Carbon nanodots: A review-From the current understanding of the fundamental photophysics to the full control of the optical response. C 2018, 4, 67. [CrossRef]

6. Kelarakis, A. From highly graphitic to amorphous carbon dots: A critical review. MRS Energy Sustain. 2014, 1, 2. [CrossRef]

7. Kelarakis, A. Graphene quantum dots: In the crossroad of graphene, quantum dots and carbogenic nanoparticles. Curr. Opin. Colloid Interface Sci. 2015, 20, 354-361. [CrossRef]

8. Ding, X. Direct synthesis of graphene quantum dots on hexagonal boron nitride substrate. J. Mater. Chem. C 2014, 2, 3717-3722. [CrossRef]

9. Yan, X.; Cui, X.; Li, B.; Li, L.-S. Large, solution-processable graphene quantum dots as light absorbers for photovoltaics. Nano Lett. 2010, 10, 1869-1873. [CrossRef]

10. Lu, J.; Yeo, P.S.E.; Gan, C.K.; Wu, P.; Loh, K. Transforming $\mathrm{C}_{60}$ molecules into graphene quantum dots. Nat. Nanotechnol. 2011, 6, 247-252. [CrossRef]

11. Ye, R.; Xiang, C.; Lin, J.; Peng, Z.; Huang, K.; Yan, Z.; Cook, N.P.; Samuel, E.; Hwang, C.-C.; Ruan, G.; et al. Coal as an abundant source of graphene quantum dots. Nat. Commun. 2013, 4, 2943. [CrossRef] [PubMed]

12. Dong, Y.; Chen, C.; Zheng, X.T.; Gao, L.; Cui, Z.; Yang, H.; Guo, C.; Chi, Y.; Li, C.M. One-step and high yield simultaneous preparation of single- and multi-layer graphene quantum dots from CX-72 carbon black. J. Mater. Chem. 2012, 22, 8764-8766. [CrossRef]

13. Pan, D.; Zhang, J.; Li, Z.; Wu, M. Hydrothermal route for cutting graphene sheets into blue-luminescent graphene quantum dots. Adv. Mater. 2010, 22, 734-738. [CrossRef] [PubMed]

14. Peng, J.; Gao, W.; Gupta, B.K.; Liu, Z.; Romero-Aburto, R.; Ge, L.; Song, L.; Alemany, L.B.; Zhan, X.; Gao, G.; et al. Graphene quantum dots derived from carbon fibers. Nano Lett. 2012, 12, 844-849. [CrossRef]

15. Zhou, J.; Booker, C.; Li, R.; Zhou, X.; Sham, T.-K.; Sun, X.; Ding, Z. An electrochemical avenue to blue luminescent nanocrystals from multiwalled carbon nanotubes (MWCNTs). J. Am. Chem. Soc. 2007, 129, 744-745. [CrossRef]

16. Krysmann, M.J.; Kelarakis, A.; Giannelis, E.P. Photoluminescent carbogenic nanoparticles directly derived from crude biomass. Green Chem. 2012, 14, 3141-3145. [CrossRef]

17. Zhang, X.; Wang, H.; Ma, C.; Niu, N.; Chen, Z.; Liu, S.; Li, J.; Li, S. Seeking value from biomass materials: Preparation of coffee bean shell-derived fluorescent carbon dots via molecular aggregation for antioxidation and bioimaging applications. Mater. Chem. Front. 2018, 2, 1269-1275. [CrossRef]

18. Huang, H.; Lv, J.-J.; Zhou, D.-L.; Bao, N.; Xu, Y.; Wang, A.-J.; Feng, J.-J. One-pot green synthesis of nitrogen-doped carbon nanoparticles as fluorescent probes for mercury ions. RSC Adv. 2013, 3, 21691-21696. [CrossRef]

19. Krysmann, M.J.; Kelarakis, A.; Dallas, P.; Giannelis, E.P. Formation mechanism of carbogenic nanoparticles with dual photoluminescence emission. J. Am. Chem. Soc. 2011, 134, 747-750. [CrossRef] [PubMed]

20. Ehrat, F.; Bhattacharyya, S.; Schneider, J.; Löf, A.; Wyrwich, R.; Rogach, A.L.; Stolarczyk, J.K.; Urban, A.S.; Feldmann, J. Tracking the source of carbon dot photoluminescence: Aromatic domains versus molecular fluorophores. Nano Lett. 2017, 17, 7710-7716. [CrossRef]

21. Kasprzyk, W.P.; Świergosz, T.; Bednarz, S.; Walas, K.; Bashmakova, N.V.; Bogdał, D. Luminescence phenomena of carbon dots derived from citric acid and urea-A molecular insight. Nanoscale 2018, 10, 13889-13894. [CrossRef] [PubMed]

22. Wu, Y.-F.; Wu, H.-C.; Kuan, C.-H.; Lin, C.-J.; Wang, L.-W.; Chang, C.-W.; Wang, T.-W. Multi-functionalized carbon dots as theranostic nanoagent for gene delivery in lung cancer therapy. Sci. Rep. 2016, 6, 21170. [CrossRef] [PubMed]

23. Ding, H.; Du, F.; Liu, P.; Chen, Z.; Shen, J. DNA-Carbon dots function as fluorescent vehicles for drug delivery. ACS Appl. Mater. Interfaces 2015, 7, 6889-6897. [CrossRef] [PubMed]

24. Song, Y.; Lu, F.; Li, H.; Wang, H.; Zhang, M.; Liu, Y.; Kang, Z. Degradable carbon dots from cigarette smoking with broad-spectrum antimicrobial activities against drug-resistant bacteria. ACS Appl. Bio Mater. 2018, 1, 1871-1879. [CrossRef]

25. Li, H.; Yan, X.; Kong, D.; Jin, R.; Sun, C.; Du, D.; Lin, Y.; Lu, G. Recent advances in carbon dots for bioimaging applications. Nanoscale Horiz. 2019, 5, 218-234. [CrossRef]

26. Huang, S.; Li, W.; Han, P.; Zhou, X.; Cheng, J.; Wen, H.; Xue, W. Carbon quantum dots: Synthesis, properties, and sensing applications as a potential clinical analytical method. Anal. Methods 2019, 11, 2240-2258. [CrossRef]

27. Fernandes, D.; Heslop, K.; Kelarakis, A.; Krysmann, M.; Estevez, L. In situ generation of carbon dots within a polymer matrix. Polymer 2020, 188, 122159. [CrossRef]

28. Bhunia, S.K.; Nandi, S.; Shikler, R.; Jelinek, R. Tuneable light-emitting carbon-dot/polymer flexible films prepared through one-pot synthesis. Nanoscale 2016, 8, 3400-3406. [CrossRef] 
29. Fernandes, D.; Krysmann, M.J.; Kelarakis, A. Carbon dot based nanopowders and their application for fingerprint recovery. Chem. Commun. 2015, 51, 4902-4905. [CrossRef]

30. Verhagen, A.; Kelarakis, A. Carbon dots for forensic applications: A critical review. Nanomaterials 2020, 10, 1535. [CrossRef]

31. He, P.; Shi, Y.; Meng, T.; Yuan, T.; Li, Y.; Li, X.; Zhang, Y.; Fan, L.; Yang, S. Recent advances in white light-emitting diodes of carbon quantum dots. Nanoscale 2020, 12, 4826-4832. [CrossRef] [PubMed]

32. Rosso, C.; Filippini, G.; Prato, M. Carbon dots as nano-organocatalysts for synthetic applications. ACS Catal. 2020, 10, 8090-8105. [CrossRef]

33. Havrdova, M.; Hola, K.; Skopalik, J.; Tománková, K.B.; Petr, M.; Cepe, K.; Polakova, K.; Tucek, J.; Bourlinos, A.B.; Zboril, R. Toxicity of carbon dots-Effect of surface functionalization on the cell viability, reactive oxygen species generation and cell cycle. Carbon 2016, 99, 238-248. [CrossRef]

34. Fasbender, S.; Zimmermann, L.; Cadeddu, R.-P.; Luysberg, M.; Moll, B.; Janiak, C.; Heinzel, T.; Haas, R. The low toxicity of graphene quantum dots is reflected by marginal gene expression changes of primary human hematopoietic stem cells. Sci. Rep. 2019, 9, 1-13. [CrossRef]

35. Ding, H.; Zhou, X.-X.; Wei, J.-S.; Li, X.-B.; Qin, B.-T.; Chen, X.-B.; Xiong, H.-M. Carbon dots with red/near-infrared emissions and their intrinsic merits for biomedical applications. Carbon 2020, 167, 322-344. [CrossRef]

36. Zhu, Z.; Zhai, Y.; Li, Z.; Zhu, P.; Mao, S.; Zhu, C.; Du, D.; Belfiore, L.A.; Tang, J.; Lin, Y. Red carbon dots: Optical property regulations and applications. Mater. Today 2019, 30, 52-79. [CrossRef]

37. Liang, W.; Wang, P.; Meziani, M.J.; Ge, L.; Yang, L.; Patel, A.K.; Morgan, S.O.; Sun, Y.-P. On the myth of "red/near-IR carbon quantum dots" from thermal processing of specific colorless organic precursors. Nanoscale Adv. 2021, 3, 4186-4195. [CrossRef]

38. Miao, S.; Liang, K.; Zhu, J.; Yang, B.; Zhao, D.; Kong, B. Hetero-atom-doped carbon dots: Doping strategies, properties and applications. Nano Today 2020, 33, 100879. [CrossRef]

39. Hola, K.; Sudolská, M.; Kalytchuk, S.; Nachtigallová, D.; Rogach, A.L.; Otyepka, M.; Zbořil, R. Graphitic nitrogen triggers red fluorescence in carbon dots. ACS Nano 2016, 11, 12402-12410. [CrossRef]

40. Ding, H.; Ji, Y.; Wei, J.-S.; Gao, Q.-Y.; Zhou, Z.-Y.; Xiong, H.-M. Facile synthesis of red-emitting carbon dots from pulp-free lemon juice for bioimaging. J. Mater. Chem. B 2017, 5, 5272-5277. [CrossRef]

41. Guo, L.; Ge, J.; Liu, W.; Niu, G.; Jia, Q.; Wang, H.; Wang, P. Tunable multicolor carbon dots prepared from well-defined polythiophene derivatives and their emission mechanism. Nanoscale 2016, 8, 729-734. [CrossRef] [PubMed]

42. Pan, L.; Sun, S.; Zhang, A.; Jiang, K.; Zhang, L.; Dong, C.; Huang, Q.; Wu, A.; Lin, H. Truly fluorescent excitation-dependent carbon dots and their applications in multicolor cellular imaging and multidimensional sensing. Adv. Mater. 2015, 27, 7782-7787. [CrossRef] [PubMed]

43. Pan, L.; Sun, S.; Zhang, L.; Jiang, K.; Lin, H. Near-infrared emissive carbon dots for two-photon fluorescence bioimaging. Nanoscale 2016, 8, 17350-17356. [CrossRef] [PubMed]

44. Huang, S.; Yang, E.; Yao, J.; Liu, Y.; Xiao, Q. Red emission nitrogen, boron, sulfur co-doped carbon dots for "on-off-on" fluorescent mode detection of $\mathrm{Ag}^{+}$ions and l-cysteine in complex biological fluids and living cells. Anal. Chim. Acta 2018, 1035, 192-202. [CrossRef]

45. Xu, J.; Li, J.; Wang, C.; Zhao, W. Preparation and application of solvent-modulated self-doped N-S multicolour fluorescence carbon quantum dots. Luminescence 2019, 35, 34-42. [CrossRef]

46. Miao, X.; Yan, X.; Qu, D.; Li, D.; Tao, F.F.; Sun, Z. Red emissive sulfur, nitrogen codoped carbon dots and their application in ion detection and theraonostics. ACS Appl. Mater. Interfaces 2017, 9, 18549-18556. [CrossRef] [PubMed]

47. Ge, J.; Jia, Q.; Liu, W.; Guo, L.; Liu, Q.; Lan, M.; Zhang, H.; Meng, X.; Wang, P. Red-emissive carbon dots for fluorescent, photoacoustic, and thermal theranostics in living mice. Adv. Mater. 2015, 27, 4169-4177. [CrossRef] [PubMed]

48. Yang, X.; Cui, F.; Ren, R.; Sun, J.; Ji, J.; Pi, F.; Zhang, Y.; Sun, X. Red-emissive carbon dots for "switch-on" dual function sensing platform rapid detection of ferric ions and l-cysteine in living cells. ACS Omega 2019, 4, 12575-12583. [CrossRef]

49. Karami, S.; Shamsipur, M.; Taherpour, A.A.; Jamshidi, M.; Barati, A. In situ chromophore doping: A new mechanism for the long-wavelength emission of carbon dots. J. Phys. Chem. C 2020, 124, 10638-10646. [CrossRef]

50. Zhang, R.; Bertran, E.; Lee, S.-T. Size dependence of energy gaps in small carbon clusters: The origin of broadband luminescence. Diam. Relat. Mater. 1998, 7, 1663-1668. [CrossRef]

51. Li, H.; He, X.; Kang, Z.; Huang, H.; Liu, Y.; Liu, J.; Lian, S.; Tsang, A.C.H.; Yang, X.; Lee, S.-T. Water-soluble fluorescent carbon quantum dots and photocatalyst design. Angew. Chem. Int. Ed. 2010, 49, 4430-4434. [CrossRef] [PubMed]

52. Alam, M.; Ananthanarayanan, A.; Huang, L.; Lim, K.H.; Chen, P. Revealing the tunable photoluminescence properties of graphene quantum dots. J. Mater. Chem. C 2014, 2, 6954-6960. [CrossRef]

53. Hai, X.; Feng, J.; Chen, X.; Wang, J.-H. Tuning the optical properties of graphene quantum dots for biosensing and bioimaging. J. Mater. Chem. B 2018, 6, 3219-3234. [CrossRef] [PubMed]

54. Yeh, T.-F.; Huang, W.-L.; Chung, C.-J.; Chiang, I.-T.; Chen, L.-C.; Chang, H.-Y.; Su, W.-C.; Cheng, C.; Chen, S.-J.; Teng, H. elucidating quantum confinement in graphene oxide dots based on excitation-wavelength-independent photoluminescence. $J$. Phys. Chem. Lett. 2016, 7, 2087-2092. [CrossRef]

55. Yuan, F.; Wang, Z.; Li, X.; Li, Y.; Tan, Z.; Fan, L.; Yang, S. Bright multicolor bandgap fluorescent carbon quantum dots for electroluminescent light-emitting diodes. Adv. Mater. 2016, 29, 1604436. [CrossRef] [PubMed] 
56. Tian, Z.; Zhang, X.; Li, D.; Zhou, D.; Jing, P.; Shen, D.; Qu, S.; Zboril, R.; Rogach, A.L. Full-color inorganic carbon dot phosphors for white-light-emitting diodes. Adv. Opt. Mater. 2017, 5, 1700416. [CrossRef]

57. Zhu, S.; Zhang, J.; Tang, S.; Qiao, C.; Wang, L.; Wang, H.; Liu, X.; Li, B.; Li, Y.; Yu, W.; et al. Surface chemistry routes to modulate the photoluminescence of graphene quantum dots: From fluorescence mechanism to up-conversion bioimaging applications. Adv. Funct. Mater. 2012, 22, 4732-4740. [CrossRef]

58. Jin, S.H.; Kim, D.H.; Jun, G.H.; Hong, S.H.; Jeon, S. Tuning the photoluminescence of graphene quantum dots through the charge transfer effect of functional groups. ACS Nano 2013, 7, 1239-1245. [CrossRef]

59. Wang, S.; Cole, I.; Zhao, D.; Li, Q. The dual roles of functional groups in the photoluminescence of graphene quantum dots. Nanoscale 2015, 8, 7449-7458. [CrossRef]

60. Ding, H.; Yu, S.-B.; Wei, J.-S.; Xiong, H.-M. Full-color light-emitting carbon dots with a surface-state-controlled luminescence mechanism. ACS Nano 2015, 10, 484-491. [CrossRef]

61. Tian, Y.; Li, L.; Guo, X.; Wojtowicz, A.; Estevez, L.; Krysmann, M.J.; Kelarakis, A. Dramatic photoluminescence quenching in carbon dots induced by cyclic voltammetry. Chem. Commun. 2018, 54, 9067-9070. [CrossRef]

62. Liu, C.; Wang, R.; Wang, B.; Deng, Z.; Jin, Y.; Kang, Y.; Chen, J. Orange, yellow and blue luminescent carbon dots controlled by surface state for multicolor cellular imaging, light emission and illumination. Microchim. Acta 2018, 185, 539. [CrossRef] [PubMed]

63. Zhang, Z.; Pan, Y.; Fang, Y.; Zhang, L.; Chen, J.; Yi, C. Tuning photoluminescence and surface properties of carbon nanodots for chemical sensing. Nanoscale 2015, 8, 500-507. [CrossRef]

64. Bao, L.; Liu, C.; Zhang, Z.-L.; Pang, D.-W. Photoluminescence-tunable carbon nanodots: Surface-state energy-gap tuning. Adv. Mater. 2015, 27, 1663-1667. [CrossRef]

65. Sciortino, A.; Marino, E.; Van Dam, B.; Schall, P.; Cannas, M.; Messina, F. Solvatochromism unravels the emission mechanism of carbon nanodots. J. Phys. Chem. Lett. 2016, 7, 3419-3423. [CrossRef] [PubMed]

66. Zheng, M.; Li, Y.; Zhang, Y.; Xie, Z. Solvatochromic fluorescent carbon dots as optic noses for sensing volatile organic compounds. RSC Adv. 2016, 6, 83501-83504. [CrossRef]

67. Reckmeier, C.J.; Wang, Y.; Zboril, R.; Rogach, A.L. Influence of doping and temperature on solvatochromic shifts in optical spectra of carbon dots. J. Phys. Chem. C 2016, 120, 10591-10604. [CrossRef]

68. Wang, H.; Haydel, P.; Sui, N.; Wang, L.; Liang, Y.; Yu, W.W. Wide emission shifts and high quantum yields of solvatochromic carbon dots with rich pyrrolic nitrogen. Nano Res. 2020, 13, 2492-2499. [CrossRef]

69. Wang, H.; Sun, C.; Chen, X.; Zhang, Y.; Colvin, V.L.; Rice, Q.; Seo, J.; Feng, S.; Wang, S.; Yu, W.W. Excitation wavelength independent visible color emission of carbon dots. Nanoscale 2017, 9, 1909-1915. [CrossRef] [PubMed]

70. Li, D.; Jing, P.; Sun, L.; An, Y.; Shan, X.; Lu, X.; Zhou, D.; Han, D.; Shen, D.; Zhai, Y.; et al. Near-infrared excitation/emission and multiphoton-induced fluorescence of carbon dots. Adv. Mater. 2018, 30, e1705913. [CrossRef]

71. Yang, S.; Zhu, C.; Sun, J.; He, P.; Yuan, N.; Ding, J.; Ding, G.; Xie, X. Triphenylphosphine modified graphene quantum dots: Spectral modulation for full spectrum of visible light with high quantum yield. RSC Adv. 2015, 5, 33347-33350. [CrossRef]

72. Liu, J.; Li, D.; Zhang, K.; Yang, M.; Sun, H.; Yang, B. One-step hydrothermal synthesis of nitrogen-doped conjugated carbonized polymer dots with 31\% efficient red emission for in vivo imaging. Small 2018, 14, e1703919. [CrossRef] [PubMed]

73. Tan, X.; Li, Y.; Li, X.; Zhou, S.; Fan, L.; Yang, S. Electrochemical synthesis of small-sized red fluorescent graphene quantum dots as a bioimaging platform. Chem. Commun. 2015, 51, 2544-2546. [CrossRef] [PubMed]

74. Li, C.; Wang, Y.; Zhang, X.; Guo, X.; Kang, X.; Du, L.; Liu, Y. Red fluorescent carbon dots with phenylboronic acid tags for quick detection of Fe(III) in PC12 cells. J. Colloid Interface Sci. 2018, 526, 487-496. [CrossRef] [PubMed]

75. Gao, W.; Song, H.; Wang, X.; Liu, X.; Pang, X.; Zhou, Y.; Gao, B.; Peng, X. Carbon dots with red emission for sensing of Pt ${ }^{2+}$, Au ${ }^{3+}$ and $\mathrm{Pd}^{2+}$ and their bioapplications in vitro and in vivo. ACS Appl. Mater. Interfaces 2017, 10, 1147-1154. [CrossRef] [PubMed]

76. Jia, Q.; Zheng, X.; Ge, J.; Liu, W.; Ren, H.; Chen, S.; Wen, Y.; Zhang, H.; Wu, J.; Wang, P. Synthesis of carbon dots from Hypocrella bambusae for bimodel fluorescence/photoacoustic imaging-guided synergistic photodynamic/photothermal therapy of cancer. J. Colloid Interface Sci. 2018, 526, 302-311. [CrossRef] [PubMed]

77. Ge, J.; Lan, M.; Zhou, B.; Liu, W.; Guo, L.; Wang, H.; Jia, Q.; Niu, G.; Huang, X.; Zhou, H.; et al. A graphene quantum dot photodynamic therapy agent with high singlet oxygen generation. Nat. Commun. 2014, 5, 4596. [CrossRef]

78. Yuan, B.; Guan, S.; Sun, X.; Li, X.; Zeng, H.; Xie, Z.; Chen, P.; Zhou, S. Highly efficient carbon dots with reversibly switchable green-red emissions for trichromatic white light-emitting diodes. ACS Appl. Mater. Interfaces 2018, 10, 16005-16014. [CrossRef]

79. Jin, L.; Zhang, L.; Yang, L.; Wu, X.; Zhang, C.; Wei, K.; He, L.; Han, X.; Qiao, H.; Asiri, A.M.; et al. Orange-red, green, and blue fluorescence carbon dots for white light emitting diodes. J. Mater. Sci. Technol. 2020, 50, 184-191. [CrossRef]

80. Zhang, B.; Yang, J.; Li, H. Multiple color emission of solid-state hybrid material containing carbon dots and Europium(III) complexes. J. Lumin. 2019, 220, 116959. [CrossRef]

81. Yuan, R.; Liu, J.; Xiang, W.; Liang, X. Red-emitting carbon dots phosphors: A promising red color convertor toward warm white light emitting diodes. J. Mater. Sci. Mater. Electron. 2018, 29, 10453-10460. [CrossRef]

82. Jiang, B.; Zhou, B.; Shen, X.; Yu, Y.; Ji, S.; Wen, C.; Liang, H. Selective probing of gaseous ammonia using red-emitting carbon dots based on an interfacial response mechanism. Chem. Eur. J. 2015, 21, 18993-18999. [CrossRef] [PubMed]

83. Lu, H.; Xu, S.; Liu, J. One pot generation of blue and red carbon dots in one binary solvent system for dual channel detection of $\mathrm{Cr}^{3+}$ and $\mathrm{Pb}^{2+}$ based on ion imprinted fluorescence polymers. ACS Sens. 2019, 4, 1917-1924. [CrossRef] [PubMed] 
84. Hu, Y.; Gao, Z.; Luo, J. Fluorescence detection of malachite green in fish tissue using red emissive Se, N, Cl-doped carbon dots. Food Chem. 2020, 335, 127677. [CrossRef] [PubMed]

85. Li, F.; Wang, X.; Liu, W.; Wang, L.; Wang, G. One-step solvothermal synthesis of red emissive carbonized polymer dots for latent fingerprint imaging. Opt. Mater. 2018, 86, 79-86. [CrossRef]

86. Yuan, K.; Zhang, X.; Li, X.; Qin, R.; Cheng, Y.; Li, L.; Yang, X.; Yu, X.; Lu, Z.; Liu, H. Great enhancement of red emitting carbon dots with B/Al/Ga doping for dual mode anti-counterfeiting. Chem. Eng. J. 2020, 397, 125487. [CrossRef]

87. Stachowska, J.D.; Murphy, A.; Mellor, C.; Fernandes, D.; Gibbons, E.N.; Krysmann, M.J.; Kelarakis, A.; Burgaz, E.; Moore, J.; Yeates, S.G. A rich gallery of carbon dots based photoluminescent suspensions and powders derived by citric acid/urea. Sci. Rep. 2021, 11, 1-14. [CrossRef]

88. Kong, B.; Tang, J.; Zhang, Y.; Jiang, T.; Gong, X.; Peng, C.; Wei, J.; Yang, J.; Wang, Y.; Wang, X.; et al. Incorporation of well-dispersed sub-5-nm graphitic pencil nanodots into ordered mesoporous frameworks. Nat. Chem. 2015, 8, 171-178. [CrossRef]

89. Miao, S.; Liang, K.; Kong, B. Förster resonance energy transfer (FRET) paired carbon dot-based complex nanoprobes: Versatile platforms for sensing and imaging applications. Mater. Chem. Front. 2019, 4, 128-139. [CrossRef]

90. Kundelev, E.V.; Tepliakov, N.V.; Leonov, M.Y.; Maslov, V.G.; Baranov, A.; Fedorov, A.; Rukhlenko, I.; Rogach, A.L. Towards bright red-emissive carbon dots through controlling interaction among surface emission centers. J. Phys. Chem. Lett. 2020, 11, 8121-8127. [CrossRef]

91. Zheng, M.; Qiao, L.; Su, Y.; Gao, P.; Xie, Z. A postmodification strategy to modulate the photoluminescence of carbon dots from blue to green and red: Synthesis and applications. J. Mater. Chem. B 2019, 7, 3840-3845. [CrossRef]

92. Li, D.; Li, W.; Zhang, H.; Zhang, X.; Zhuang, J.; Liu, Y.; Hu, C.; Lei, B. Far-red carbon dots as efficient light-harvesting agents for enhanced photosynthesis. ACS Appl. Mater. Interfaces 2020, 12, 21009-21019. [CrossRef] [PubMed]

93. Ding, H.; Wei, J.S.; Zhong, N.; Gao, Q.Y.; Xiong, H.M. Highly efficient red-emitting carbon dots with gram-scale yield for bioimaging. Langmuir 2017, 33, 12635-12642. [CrossRef] [PubMed]

94. Liu, Y.; Gou, H.; Huang, X.; Zhang, G.; Xi, K.; Jia, X. Rational synthesis of highly efficient ultra-narrow red-emitting carbon quantum dots for NIR-II two-photon bioimaging. Nanoscale 2019, 12, 1589-1601. [CrossRef] [PubMed]

95. Bhati, A.; Anand, S.R.; Gunture; Garg, A.K.; Khare, P.; Sonkar, S.K. Sunlight-induced photocatalytic degradation of pollutant dye by highly fluorescent red-emitting mg-n-embedded carbon dots. ACS Sustain. Chem. Eng. 2018, 6, 9246-9256. [CrossRef]

96. Li, L.; Zhang, R.; Lu, C.; Sun, J.; Wang, L.; Qu, B.; Li, T.; Liu, Y.; Li, S. In situ synthesis of NIR-light emitting carbon dots derived from spinach for bio-imaging applications. J. Mater. Chem. B 2017, 5, 7328-7334. [CrossRef] 